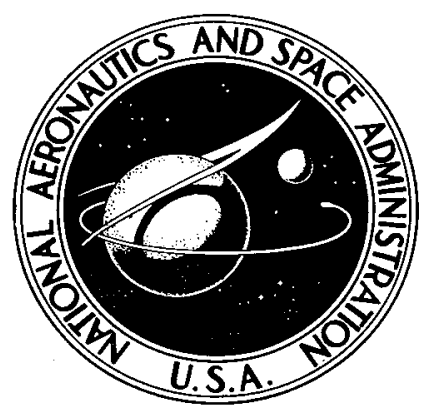

NASA TN D-7385

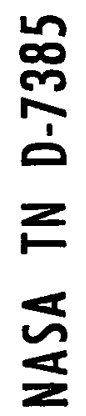

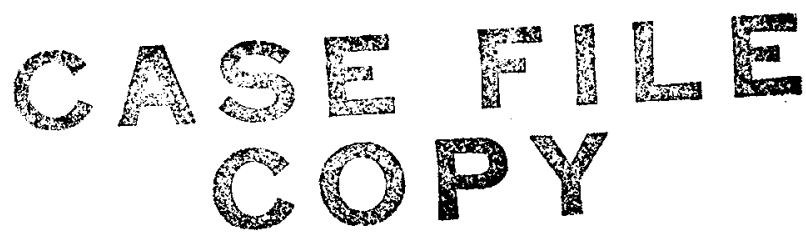

FORTRAN IV COMPUTER PROGRAM FOR CALCULATING CRITICAL SPEEDS OF ROTATING SHAFTS

by Roger J. Trivisonno

Lewis Research Center

Cleveland, Obio 44135

NATIONAL AERONAUTICS AND SPACE ADMINISTRATION - WASHINGTON, D. C. • AUGUST 1973 


\begin{tabular}{|c|c|c|c|}
\hline 1. $\mathrm{R}$ & 2. Government Accession No. & \multicolumn{2}{|c|}{ 3. Recipient's Catalog No. } \\
\hline \multirow{2}{*}{\multicolumn{2}{|c|}{$\begin{array}{l}\text { 4. Title and Subtitle } \\
\text { FORTRAN IV COMPUTER PROGRAM FOR CALCULATING } \\
\text { CRITICAL SPEEDS OF ROTATING SHAFTS }\end{array}$}} & \multicolumn{2}{|c|}{$\begin{array}{l}\text { 5. Report Date } \\
\text { August } 1973\end{array}$} \\
\hline & & \multicolumn{2}{|c|}{ 6. Performing Organization Code } \\
\hline \multirow{2}{*}{$\begin{array}{l}\text { 7. Author(s) } \\
\text { Roger J. Trivisonno }\end{array}$} & & \multicolumn{2}{|c|}{$\begin{array}{l}\text { 8. Performing Organization Report No. } \\
\text { E-7017 }\end{array}$} \\
\hline \multirow{3}{*}{\multicolumn{2}{|c|}{$\begin{array}{l}\text { 9. Performing Organization Name and Address } \\
\text { Lewis Research Center } \\
\text { National Aeronautics and Space Administration } \\
\text { Cleveland, Ohio } 44135\end{array}$}} & \multicolumn{2}{|l|}{$\begin{array}{l}\text { 10. Work Unit No. } \\
501-24\end{array}$} \\
\hline & & \multicolumn{2}{|c|}{ 11. Contract or Grant No. } \\
\hline & & \multirow{2}{*}{\multicolumn{2}{|c|}{$\begin{array}{l}\text { 13. Type of Report and Period Covered } \\
\text { Technical Note }\end{array}$}} \\
\hline \multirow{2}{*}{\multicolumn{2}{|c|}{$\begin{array}{l}\text { 12. Sponsoring Agency Name and Address } \\
\text { National Aeronautics and Space Administration } \\
\text { Washington, D.C. } 20546\end{array}$}} & & \\
\hline & & \multicolumn{2}{|c|}{ 14. Sponsoring Agency Code } \\
\hline \multicolumn{4}{|c|}{ 15. Supplementary Notes } \\
\hline \multicolumn{4}{|c|}{$\begin{array}{l}\text { 16. Abstract } \\
\text { This report describes a FORTRAN IV computer program, written for the IBM DCS } 7094 / 7044 \\
\text { computer, that calculates the critical speeds of rotating shafts. The shaft may include bear- } \\
\text { ings, couplings, extra masses (nonshaft mass), and disks for the gyroscopic effect. Shear } \\
\text { deflection is also taken into account, and provision is made in the program for sections of the } \\
\text { shaft that are tapered. The boundary conditions at the ends of the shaft can be fixed (deflec- } \\
\text { tion and slope equal to zero) or free (shear and moment equal to zero). The fixed end condi- } \\
\text { tion enables the program to calculate the natural frequencies of cantilever beams. Instead of } \\
\text { using the lumped-parameter method, the program uses continuous integration of the differen- } \\
\text { tial equations of beam flexure across different shaft sections. The advantages of this method } \\
\text { over the usual lumped-parameter method are less data preparation and better approximation } \\
\text { of the distribution of the mass of the shaft. A main feature of the program is the nature of } \\
\text { the output. The Calcomp plotter is used to produce a drawing of the shaft with superimposed } \\
\text { deflection curves at the critical speeds, together with all pertinent information related to the } \\
\text { shaft. }\end{array}$} \\
\hline $\begin{aligned} & 17 . k \\
& \\
& \\
& \\
&\end{aligned}$ & $\begin{array}{l}\text { 18. Distribution } \\
\text { Unclass: }\end{array}$ & unlimited & \\
\hline 19. 5 & $\begin{array}{l}\text { of this page) } \\
\text { sified }\end{array}$ & \begin{tabular}{|c|c|} 
21. No. of Pages \\
54
\end{tabular} & $\begin{array}{l}\text { 22. Price }{ }^{*} \\
\$ 3.00\end{array}$ \\
\hline
\end{tabular}

*For sale by the National Technical Information Service, Springfield, Virginia 22151 


\section{CONTENTS}

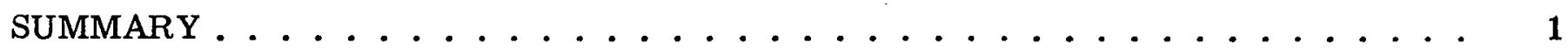

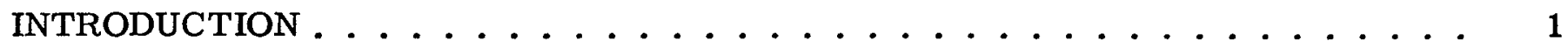

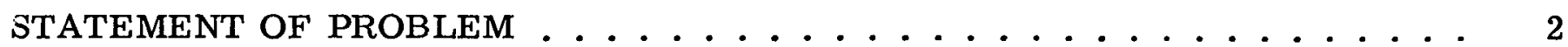

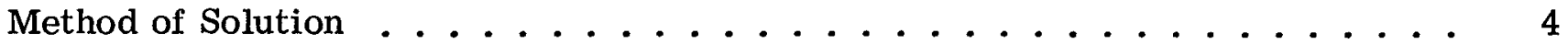

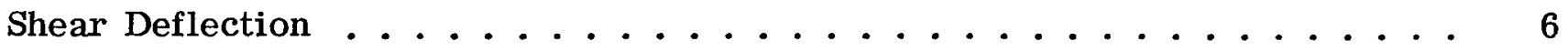

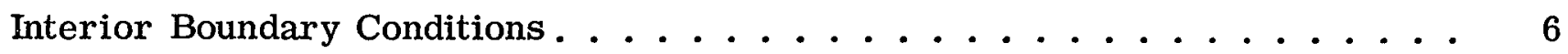

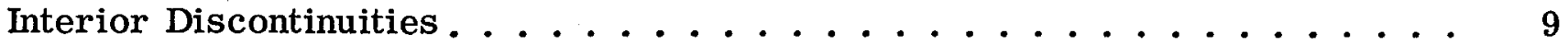

Deflection Curve Calculation ................. 10

COMPUTER PROGRAM ......................... 11

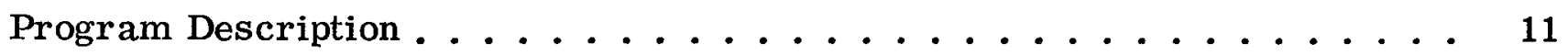

FORTRAN Symbols for NAMELIST Card . . . . . . . . . . . . 12

DATA INPUT $\ldots \ldots \ldots \ldots \ldots \ldots \ldots$



Preparation of Shaft Data Cards . . . . . . . . . . . . . 15

Sample Problems with Output . . . . . . . . . . . . . 19

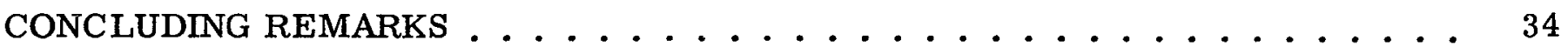

\section{APPENDIXES}

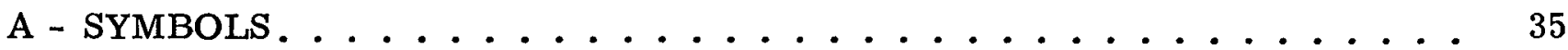

B - LISTING OF FORTRAN PROGRAM . . . . . . . . . . 37

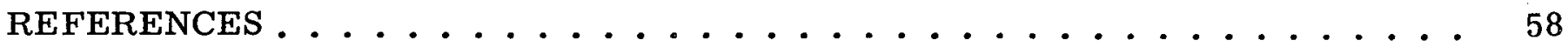




\title{
FORTRAN IV COMPUTER PROGRAM FOR CALCULATING CRITICAL SPEEDS OF ROTATING SHAFTS
}

\author{
by Roger J. Trivisonno
}

Lewis Research Center

\section{SUMMARY}

This report describes a FORTRAN IV computer program, written for the IBM DCS $7094 / 7044$ computer, that calculates the critical speeds of rotating shafts. The shaft may include bearings, couplings, extra masses (nonshaft mass), and disks for the gyroscopic effect. Shear deflection is also taken into account, and provision is made in the program for sections of the shaft that are tapered. The boundary conditions at the ends of the shaft can be fixed (deflection and slope equal to zero) or free (shear and moment equal to zero). The fixed end condition enables the program to calculate the natural frequencies of cantilever beams. Instead of using the lumped-parameter method, the program uses continuous integration of the differential equations of beam flexure across different shaft sections. The advantages of this method over the usual lumped-parameter method are less data preparation and better approximation of the distribution of the mass of the shaft.

A main feature of the program is the nature of the output. The Calcomp plotter is used to produce a drawing of the shaft with superimposed deflection curves at the critical speeds, together with all pertinent information related to the shaft.

\section{INTRODUCTION}

Most methods of calculating critical speeds are based on the lumped-parameter method, such as that of Prohl (ref. 1). This lumped-parameter technique consists in transforming a shaft system into a series of mass points so that their spacing approximates the distribution of the mass in the actual shaft. The next step is to integrate from mass point to mass point for the purpose of determining the shear, moment, slope, and deflection at each mass point. Consequently, in order to represent accurately the mass distribution of a shaft system, a considerable amount of data preparation is necessary. 
This is especially true for sections of the shaft that are tapered, where it is necessary to approximate the taper with a series of small increments.

The method described in this report improves on the lumped-parameter method by integrating along each shaft section by means of the fourth-order numerical integration technique of Runge-Kutta. The advantages of this method are that both the time for data preparation and the chance for input error are considerably reduced and that the distribution of the mass of the shaft is better approximated.

The three main sections of this report are STATEMENT OF PROBLEM, COMPUTER PROGRAM, and the appendixes. The first section contains the statement of the problem along with the method of solution. The second section contains the program description, the FORTRAN symbols for the NAMELIST card, and the method in which a shaft system is broken down in sections and stations for proper input to the program. Also, this section presents example problems, together with printed and plotted output, demonstrating the flexibility of the program. Finally, the appendixes contain the definitions of symbols and the listing of the FORTRAN program.

\section{STATEMENT OF PROBLEM}

A shaft of variable diameter, mass density, and modulus of elasticity having bear ings, couplings, disks, and extra masses (nonshaft mass) is defined to be a complex shaft system. When such a system is rotating steadily at a critical speed $\omega$, the following boundary value problem has a solution:

$$
\frac{d}{d x^{2}}\left(E I \frac{d^{2} Y}{d x^{2}}\right)=\eta \omega^{2} Y
$$

where

$$
\frac{d V}{d x}=\eta \omega^{2} Y \quad \frac{d M}{d x}=V \quad M=E I \frac{d^{2} Y}{d x^{2}} \quad \frac{d Y}{d x}=\theta
$$

$\mathrm{E}(\mathrm{x})$ modulus of elasticity at $\mathrm{x}, \mathrm{lb} / \mathrm{in} .^{2}$

$\mathrm{I}(\mathrm{x})$ diametral moment of inertia at $\mathrm{x}$, in. 4

$\eta(\mathrm{x}) \quad$ mass per unit length of a general cross section, $1 \mathrm{~b}-\mathrm{sec}^{2} / \mathrm{in}^{2}$

$\mathrm{Y}(\mathrm{x})$ deflection at $\mathrm{x}$

$\mathrm{M}(\mathrm{x})$ moment at $\mathrm{x}$ 
$\mathrm{V}(\mathrm{x}) \quad$ shear to right of $\mathrm{x}$

$\theta(\mathrm{x}) \quad$ slope at $\mathrm{x}$

$\mathrm{x} \quad$ axial position on shaft

All symbols are defined in appendix A.

The terminal boundary conditions are introduced by (1) free overhang

$$
\mathrm{M}(0)=\mathrm{V}(0)=0
$$

or (2) fixed end

$$
Y(0)=\theta(0)=0
$$

and free overhang

$$
M(L)=V(L)=0
$$

The interior boundary conditions are introduced by (1) rigid bearing at station $n$

$$
\begin{gathered}
\mathrm{Y}(\mathrm{x})=0 \\
\theta, \mathrm{M} \text { continuous }
\end{gathered}
$$

or (2) coupling at station $n$

$$
\mathbf{M}(\mathbf{x})=0
$$

$\mathrm{Y}, \mathrm{V}$ continuous

The interior discontinuities are introduced by (1) flexible bearing at station $n$

$$
\mathrm{V}\left(\mathrm{x}^{+}\right)=\mathrm{V}\left(\mathrm{x}^{-}\right)-\mathrm{KY}(\mathrm{x})
$$

(2) extra mass at station $n$

$$
\mathrm{V}\left(\mathrm{x}^{+}\right)=\mathrm{V}\left(\mathrm{x}^{-}\right)+\mathrm{S}_{\mathrm{n}} \omega^{2} \mathrm{Y}(\mathrm{x})
$$

or (3) gyroscopic disk at station $\mathrm{n}$

$$
M\left(x^{+}\right)=M\left(x^{-}\right)+(A-B) \omega^{2} \theta(x)
$$


where

$\mathrm{K}$ bearing stiffness factor (spring rate), $1 \mathrm{~b} / \mathrm{in}$.

A mass moment of inertia of disk about its axis of symmetry, $1 b-i n .-s^{2}$

B mass moment of inertia of disk about axis through center of gravity and normal to axis of symmetry, $1 b-i n .-\sec ^{2}$

$s_{n}$ nonshaft mass at station $n, 1 b-\sec ^{2} /$ in.

\section{Mêthod of Solution}

To obtain the critical speeds of a shaft system, the shaft is transformed into a series of sections and stations. Stations are axial positions on the shaft where disks, bearings, couplings, and extra masses are located or where the formulas for $\mathrm{E}, \eta$, and I change. A section is the portion of the shaft between two stations. By using the following method on a shaft system broken down in this manner, the critical speeds can be found.

The method can best be illustrated by studying a simple uniform shaft, with no interior boundary conditions or discontinuities. The boundary conditions at both ends of the shaft are free.

Equation (1) is composed of the following first-order linear differential equations of beam flexure:

$$
\begin{gathered}
\frac{d}{d x} V(x)=\eta(x) \omega^{2} Y(x) \\
\frac{d}{d x} M(x)=V(x) \\
\frac{d}{d x} \theta(x)=\frac{M(x)}{E I(x)} \\
\frac{d}{d x} Y(x)=\theta(x)
\end{gathered}
$$

To obtain a simultaneous solution for this system of equations, the fourth-order Runge-Kutta method is used. The boundary conditions at $x=0$ are used for the initial conditions. This system of equations is linear and homogeneous. The theorem of the superposition principle states that any linear combination of two solutions of a linear 
homogeneous differential equation is again a solution. Since $\mathrm{Y}(0)$ and $\theta(0)$ are unspecified, we break the problem down into the following two cases:

$$
\begin{array}{ll}
\text { Case 1 } & \text { Case 2 } \\
\mathrm{V}_{01}=0 & \mathrm{~V}_{02}=0 \\
\mathrm{M}_{01}=0 & \mathrm{M}_{02}=0 \\
\theta_{01}=0 & \theta_{02}=1 \\
\mathrm{Y}_{01}=1 & \mathrm{Y}_{02}=0
\end{array}
$$

where the subscripts denote the station and case number, respectively.

After the integration across the entire shaft is completed, the solution to the initialvalue problem with $\mathrm{Y}(0)=\mathrm{Y}_{0}$ and $\theta(0)=\theta_{0}$ is

$$
\begin{aligned}
& \mathrm{V}_{\mathrm{n}}=\mathrm{V}_{\mathrm{n} 1} \mathrm{Y}_{0}+\mathrm{V}_{\mathrm{n} 2 \theta_{0}} \\
& \mathrm{M}_{\mathrm{n}}=\mathrm{M}_{\mathrm{n} 1} \mathrm{Y}_{0}+\mathrm{V}_{\mathrm{n} 2 \theta_{0}} \\
& \theta_{\mathrm{n}}=\theta_{\mathrm{n} 1} \mathrm{Y}_{0} \theta+\theta_{\mathrm{n} 2} \theta_{0} \\
& \mathrm{Y}_{\mathrm{n}}=\mathrm{Y}_{\mathrm{n} 1} \mathrm{Y}_{0}+\mathrm{Y}_{\mathrm{n} 2} \theta_{0}
\end{aligned}
$$

Now by applying the boundary condition at $\mathrm{x}=\mathrm{L}, \mathrm{V}(\mathrm{L})=0$, in equation (6) and solving for $\theta_{0}$ and substituting in equation (7), we have:

$$
\mathrm{M}_{\mathrm{L} 3}=\mathrm{Y}_{0}\left(\mathrm{M}_{\mathrm{n} 1}-\frac{\mathrm{M}_{\mathrm{n} 2} \mathrm{~V}_{\mathrm{n} 1}}{\mathrm{~V}_{\mathrm{n} 2}}\right)
$$

When an $\omega$ is used that makes $M_{L 3}$ equal zero, we have satisfied the four boundary conditions and the problem is solved. Hence, by plotting $\mathrm{M}_{\mathrm{L3}}$, in equation (10), as a function of the assumed speed $\omega$ and noting where $\mathrm{M}_{\mathrm{L} 3}$ becomes zero, the critical speeds are obtained. 


\section{Shear Deflection}

Equation (5), which defines deflection, considers bending stresses only. There is, however, some additional deflection due to shear. Usually this is negligible; however, in cylindrical shafts with small span-to-depth ratios, stresses are likely to be high. Consequently, the deflection due to shear constitutes a considerable part of the total deflection and is taken into account by Roark (ref. 2) as follows:

$$
\frac{d}{d x} Y_{S}(x)=\frac{F(x) V(x)}{A(x) G(x)}
$$

where

$$
\begin{gathered}
\mathrm{G}(\mathrm{x})=\frac{\mathrm{E}(\mathrm{x})}{2(1+\nu)} \\
\left.\mathrm{F}(\mathrm{x})=\frac{(7+6 \nu)\left(1+\mathrm{c}^{2}\right)^{2}+(20+12 \nu) \mathrm{c}}{6(1+\nu)\left(1+\mathrm{c}^{2}\right)^{2}} \quad \text { (ref. } 3\right)
\end{gathered}
$$

$\mathrm{A}(\mathrm{x})$ is the cross-sectional area at $\mathrm{x}, \nu$ is Poisson's ratio $(=1 / 3)$, and $\mathrm{c}=\mathrm{D}_{\mathbf{i}} / \mathrm{D}_{\mathrm{o}}$.

Now subtracting equation (11) from equation (5) yields

$$
\frac{d}{d x} Y(x)=\theta(x)-\gamma(x) V(x)
$$

where

$$
\gamma(\mathrm{x})=\frac{\mathrm{F}(\mathrm{x})}{\mathrm{A}(\mathrm{x}) \mathrm{G}(\mathrm{x})}
$$

\section{Interior Boundary Conditions}

In the previous section a simple uniform shaft was used to illustrate the method of calculating critical speeds. When internal boundary conditions are added (i.e., rigid bearings and couplings), creating a multispan shaft system, the method of calculating critical speeds changes only at the boundary conditions. The explanation of these changes follows. 
Rigid bearing. - This type of bearing is infinitely stiff against displacement but of fers no restraint to tilting of the shaft. At the point on the shaft where the rigid bearing is located, $x=x_{R}$, the new boundary conditions are zero deflection, continuous $\theta$ and $\mathrm{M}$, and an unknown jump in $\mathrm{V}$.

Equations (6) to (9) define $V, M, \theta$, and $Y$ in the span from $x=0$ to $x=x_{R}$. Now when we apply the condition $Y\left(x_{R}\right)=0$ to equation (9), it follows that

$$
\mathrm{Y}(0)=\mathrm{C}_{\mathrm{R}^{\theta(0)}}
$$

where

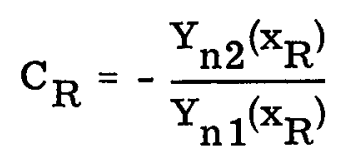

and equations (6) to (9) simplify to

$$
\begin{gathered}
\mathrm{V}_{\mathrm{n} 3}=\left(\mathrm{V}_{\mathrm{n} 2}+\mathrm{C}_{\mathrm{R}} \mathrm{V}_{\mathrm{n} 1}\right)^{\theta_{0}} \\
\mathrm{M}_{\mathrm{n} 3}=\left(\mathrm{M}_{\mathrm{n} 2}+\mathrm{C}_{\mathrm{R}} \mathrm{M}_{\mathrm{n} 1}\right)^{\theta_{0}} \\
\theta_{\mathrm{n} 3}=\left(\theta_{\mathrm{n} 2}+\mathrm{C}_{\mathrm{R}} \theta_{\mathrm{n} 1}\right) \theta_{0} \\
\mathrm{Y}_{\mathrm{n} 3}=\left(\mathrm{Y}_{\mathrm{n} 2}+\mathrm{C}_{\mathrm{R}} \mathrm{Y}_{\mathrm{n} 1}\right) \theta_{0}
\end{gathered}
$$

Since $V\left(x_{R}\right)=V_{R}$ is unspecified, the problem is broken down for the next span into the following two cases:

Case 1

$$
\begin{array}{cc}
\mathrm{V}_{\mathrm{R} 1}=1 & \mathrm{~V}_{\mathrm{R} 2}=0 \\
\mathrm{M}_{\mathrm{R} 1}=0 & \mathrm{M}_{+\mathrm{R} 2}=\mathrm{M}_{-\mathrm{R} 2}\left(\mathrm{x}_{\mathrm{R}}\right)+\mathrm{C}_{\mathrm{R}} \mathrm{M}_{-\mathrm{R} 1}\left(\mathrm{x}_{\mathrm{R}}\right) \\
{ }^{\theta_{\mathrm{R} 1}=0} & \theta_{+\mathrm{R} 2}=\theta_{-\mathrm{R} 2}\left(\mathrm{x}_{\mathrm{R}}\right)+\mathrm{C}_{\mathrm{R}} \theta_{-\mathrm{R} 1}\left(\mathrm{x}_{\mathrm{R}}\right) \\
\mathrm{Y}_{\mathrm{R} 1}=0 & \mathrm{Y}_{\mathrm{R} 2}=0
\end{array}
$$

Case 2 
For points in this span the solution to the boundary value problem with boundary conditions $\theta(0)=\theta_{0}$ and $\mathrm{V}\left(\mathrm{x}_{\mathbf{R}}\right)=\mathrm{V}_{\mathbf{R}}$ is given by

$$
\begin{gathered}
\mathrm{v}_{\mathrm{n} 3}=\mathrm{V}_{\mathrm{n} 1} \mathrm{~V}_{\mathrm{R}}+\mathrm{V}_{\mathrm{n} 2 \theta_{0}} \\
\mathrm{M}_{\mathrm{n} 3}=\mathrm{M}_{\mathrm{n} 1} \mathrm{~V}_{\mathrm{R}}+\mathrm{M}_{\mathrm{n} 2 \theta_{0}} \\
\theta_{\mathrm{n} 3}=\theta_{\mathrm{n} 1} \mathrm{~V}_{\mathrm{R}}+\theta_{\mathrm{n} 2} \theta_{0} \\
\mathrm{Y}_{\mathrm{n} 3}=\mathrm{Y}_{\mathrm{n} 1} \mathrm{~V}_{\mathrm{R}}+\mathrm{Y}_{\mathrm{n} 2 \theta_{0}}
\end{gathered}
$$

Couplings. - At the point on the shaft where a coupling is located, $x=x_{C}$, the new boundary conditions are zero moment, continuous $\mathrm{Y}$ and $\mathrm{V}$, and an unknown jump in $\theta$. Now when we apply the condition $\mathrm{M}\left(\mathrm{x}_{\mathrm{C}}\right)=0$ to equation (7), it follows that

$$
\mathrm{Y}(0)=\mathrm{C}_{\mathrm{C}^{\theta}}{ }^{(0)}
$$

where

$$
C_{C}=-\frac{M_{n 2}\left(x_{C}\right)}{M_{n 1}\left(x_{C}\right)}
$$

and equations (6) to (9) simplify to

$$
\begin{aligned}
\mathrm{V}_{\mathrm{n} 3} & =\left(\mathrm{V}_{\mathrm{n} 2}+\mathrm{C}_{\mathrm{C}} \mathrm{V}_{\mathrm{n} 1}\right)_{0} \\
\mathrm{M}_{\mathrm{n} 3} & =\left(\mathrm{M}_{\mathrm{n} 2}+\mathrm{C}_{\mathrm{C}} \mathrm{M}_{\mathrm{n} 1}\right) \theta_{0} \\
\theta_{\mathrm{n} 3} & =\left(\theta_{\mathrm{n} 2}+\mathrm{C}_{\mathrm{C}} \theta_{\mathrm{n} 1}\right) \theta_{0} \\
\mathrm{Y}_{\mathrm{n} 3} & =\left(\mathrm{Y}_{\mathrm{n} 2}+\mathrm{C}_{\mathrm{C}} \mathrm{Y}_{\mathrm{n} 1}\right)_{0}
\end{aligned}
$$

Since $\theta\left(\mathrm{x}_{\mathrm{C}}\right)=\theta_{\mathbf{C}}$ is unspecified, the problem is broken down for the next span into the following two cases: 


\section{Case 1}

$$
\begin{array}{cc}
\mathrm{V}_{\mathrm{C} 1}=0 & \mathrm{~V}_{+\mathrm{C} 2}=\mathrm{V}_{-\mathrm{C} 2}\left(\mathrm{x}_{\mathrm{C}}\right)+\mathrm{C}_{\mathrm{C}}\left(\mathrm{x}_{\mathrm{C}}\right) \\
\mathrm{M}_{\mathrm{C} 1}=0 & \mathrm{M}_{\mathrm{C} 2}=0 \\
\theta_{\mathrm{C} 1}=1 & \theta_{+\mathrm{C} 2}=0 \\
\mathrm{Y}_{\mathrm{C} 1}=0 & \mathrm{Y}_{+\mathrm{C} 2}=\mathrm{Y}_{-\mathrm{C} 2}\left(\mathrm{x}_{\mathrm{C}}\right)+\mathrm{C}_{\mathrm{C}} \mathrm{Y}_{-\mathrm{C} 1}\left(\mathrm{x}_{\mathrm{C}}\right)
\end{array}
$$

This completes the treatment on interior boundary conditions.

\section{Interior Discontinuities}

This section treats interior discontinuities introduced by flexible bearings, extra masses (nonshaft mass), and disks attached to the shaft. The flexible bearings and extra masses introduce a discontinuity in shear. A disk attached at some point on the shaft introduces to the rotating system a gyroscopic effect which causes a discontinuity in the moment. The treatment of these three cases follows.

Flexible bearing. - This type of bearing is elastic against displacement but offers no restraint to tilting of the shaft. At the point on the shaft where the flexible bearing is $10-$ cated, the shear is changed by subtracting from it the product of the spring rate $K$ of the bearing and the deflection $\mathrm{Y}(\mathrm{x})$

$$
\mathrm{V}\left(\mathrm{x}^{+}\right)=\mathrm{V}\left(\mathrm{x}^{-}\right)-\mathrm{KY}(\mathrm{x})
$$

Extra masses (nonshaft mass). - Masses that are attached to the shaft but do not contribute to the stiffness of the shaft bring about a change in shear at the point on the shaft where they are concentrated. By using the following equation, the shear to the right of the station where the mass is located can be computed:

$$
\mathrm{V}\left(\mathrm{x}^{+}\right)=\mathrm{S} \omega^{2} \mathrm{Y}(\mathrm{x})+\mathrm{V}\left(\mathrm{x}^{-}\right)
$$

where $S$ is the extra mass at $x$.

Gyroscopic effect of disks attached to shaft. - The gyroscopic effect of disks attached to the shaft can be taken into account for calculating the critical speeds by using the following formula from reference 1 : 


$$
\mathrm{M}\left(\mathrm{x}^{+}\right)=(\mathrm{A}-\mathrm{B}) \omega^{2} \theta(\mathrm{x})+\mathrm{M}\left(\mathrm{x}^{-}\right)
$$

where

A mass moment of inertia of disk about its axis of symmetry

B mass moment of inertia of disk about axis through center of gravity and normal to axis of symmetry

For a flat disk, $\mathrm{A}$ and $\mathrm{B}$ are given by

$$
\begin{gathered}
\mathrm{A}=\frac{\pi \rho \mathrm{h} \mathrm{D}_{\mathrm{d}}}{32} \\
\mathrm{~B}=\frac{\pi \rho \mathrm{hD}}{64}\left[1+\frac{4}{3}\left(\frac{\mathrm{h}}{\mathrm{D}_{\mathrm{d}}}\right)^{2}\right]
\end{gathered}
$$

\section{Deflection Curve Calculation}

An important phase of analyzing complex shaft systems is that of studying the deflection curve at a critical speed. One of the important aspects of a deflection curve is that it reveals where the greatest bending of the shaft is taking place at a critical speed. Knowledge of this nature enables the engineer to make the necessary changes in the shaft design to meet the requirements of the design running speed. As an aid to the design engineer, the program superimposes all deflection curves at the critical speeds on a drawing of the shaft.

By using the following formula, a value for $Y_{n 3}$ can be obtained for every $x_{n}$ :

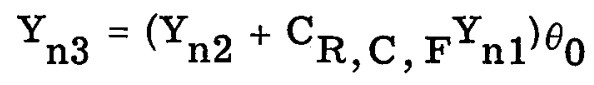

where $C_{R}$ is used from a boundary condition to a rigid bearing and is equal to $-\left[\mathrm{Y}_{\mathrm{n} 2}\left(\mathrm{x}_{\mathrm{R}}\right) / \mathrm{Y}_{\mathrm{n} 1}\left(\mathrm{x}_{\mathrm{R}}\right)\right], \mathrm{C}_{\mathrm{C}}$ is used from a boundary condition to a coupling and is equal to $-\left[\mathrm{M}_{\mathrm{n} 2}\left(\mathrm{x}_{\mathrm{C}}\right) / \mathrm{M}_{\mathrm{n} 1}\left(\mathrm{x}_{\mathrm{C}}\right)\right]$, and $\mathrm{C}_{\mathrm{F}}$ is used from a boundary condition to a free overhang and is equal to $-\left[\mathrm{V}_{\mathrm{n} 2}\left(\mathrm{x}_{\mathrm{L}}\right) / \mathrm{V}_{\mathrm{n} 1}\left(\mathrm{x}_{\mathrm{L}}\right)\right]$.

It should be noted that the deflection curve produced by equation (34) represents the shape of the deflected shaft centerline at the critical speed. It does not represent the true magnitude of the shaft deflection. 


\section{COMPUTER PROGRAM}

The critical-speed program is written in FORTRAN IV language for the IBM DCS $7094 / 7044$ computer. It is made up of a main program, six subroutines, and one library subroutine used for plotting, which is not included in this report. The program can solve a multispan shaft system for a maximum of 200 stations and any combination of bearings and couplings up to nine. See appendix B for the listing of the FORTRAN program.

The program will compute the first three critical speeds in the rpm interval specified. If more than three critical speeds are desired, another computer run is made with the rpm interval set at a higher level.

The execution time to compute a critical speed depends, of course, on the shaft length and the number of rpm increments that will be used. For example, in the section on sample computer problems, problem 1 involves a shaft 53.39 inches long with 51 shaft sections. For 150 increments of $200 \mathrm{rpm}$ each, the execution time is approximately 1 minute.

A more detailed explanation of the program follows.

\section{Program Description}

Main program CSP. - The main program performs the following functions:

(1) Reads all input data

(2) Writes all input data

(3) Sets switches to regulate the flow of the program

(4) Calculates gyroscopic data (if any)

(5) Calls subroutine MAIN

Subroutine MAIN. - This subroutine (1) sets up initial conditions for numerical integration and then calls subroutine RUNGEK; (2) performs calculations for changes brought about by extra masses, flexible and rigid bearings, couplings, and gyroscopic effects; (3) calculates critical speed and writes converged value; (4) calls subroutines GRA and PPLOT for appropriate curves and drawings.

Subroutine SUBR. - This subroutine is called by RUNGEK to calculate values of the derivatives for equations (2) to (5).

Subroutine PPLOT. - This subroutine prepares data for shaft drawings.

Subroutine GRA. - This subroutine prepares data for the following curves:

(1) Deflection

(2) Bearing against critical speed

Subroutine RUNGEK. - This subroutine (1) performs the numerical integration and (2) saves numerical values of $Y$ at every step for cases 1 and 2 . 
Subroutine CALPLT. - This subroutine plots the shaft and the superimposed deflection curves and calls CALTIT. the plots.

Subroutine CALTIT. - This subroutine writes Hollerith information and numbers on

\section{FORTRAN Symbols for NAMELIST Card}

The FORTRAN symbols for the NAMELIST cards are listed and defined in this section. The underlined symbols are those initialized by the program.

A array for mass moment of inertia of disk about its axis of symmetry

AI array for moments of inertia of sections

AREA array for areas of sections

BB array for mass moment of inertia of disk about axis through center of gravity and normal to axis of symmetry

BRG array for bearing spring constants:

$B R G=0$ - rigid bearing

$\mathrm{BRG}=-1$ - coupling

DEN array for mass density of disks

DIA array for inside diameter of disks

$\underline{D R P M}$ set equal to 200

DX array for lengths of shaft sections

E array for modulus of elasticity of shaft sections

IC switch for boundary conditions at $x=0$ :

$\mathrm{IC}=1$ - free overhang
$\mathrm{IC}=2$ - fixed end

ICM switch used for plotting:

$\frac{\mathrm{ICM}=0}{\mathrm{ICM}=1}$ - plot desired
no plot

ID array for inside diameters of shaft sections 
IH, KA switches used for reading and writing data:

$\mathrm{IH}=1$ and $\mathrm{KA}=0$ - data to be read in with FORMAT 300

$\mathrm{IH}=1$ and $\mathrm{KA}=1$ - data to be read in with FORMAT 400

$\mathrm{IH}=0$ and $\mathrm{KA}=0$ - data already read in with FORMAT 300 or to be entered through NAMELIST card

$\mathrm{IH}=0$ and $\mathrm{KA}=1$ - data already read in with FORMAT 400 or to be entered through NAMELIST card

$\underline{\text { IS }}$

ISK

IXZ

KA

KB

$\underline{\text { KL }}$

L

LOC

MOD

ND

NNN

OD

ODIA

RHO

RPM used as a subscript for BRG array; tells which bearing will be used to form

the $\mathrm{x}$-axis of the bearing-stiffness-against-critical-speed plot; IS=1

switch for the gyroscopic effect:

ISK $=0$ - no gyroscopic data

$\overline{I S K}=1$ - gyroscopic effect to be considered

ISK=2 - gyroscopic effect to be considered; data in computer

switch used to write out data for the rpm-against-excess-moment curve:

$\mathrm{IXZ}=0$ - no writeout

$\overline{\mathrm{IXZ}=1}$ - data desired

see IH

total number of bearings and couplings

array for switches that tells program how gyroscopic data will enter:

$\mathrm{KL}=0$ - THIC, DEN, DIA, and ODIA

$\overline{\mathrm{KL}=1}-\mathrm{A}$ and $\mathrm{BB}$

number of shaft sections

array for locations of disks for gyroscopic effect

switch used to modify shaft data:

MOD $=0$ - no modifications

$\overline{\mathrm{MOD}=1}$ - modifications to be made; program reads in shaft DATA cards and returns to beginning of program

number of disks

used to identify run number for critical-speed-against-bearing-stiffness plot;

$\mathrm{NNN}=1$

array for outside diameters of shaft sections

array for outside diameters of disks

array for mass densities of shaft sections

starting rpm (revolutions per minute); $\underline{\mathrm{RPM}=1}$ 
RPMF upper limit of rpm interval; RPMF $=50000$

$\mathrm{RU}$

percent used to determine maximum step size in integration;

maximum step = length of shaft multiplied by $\mathrm{RU} ; \underline{\mathrm{RU}=.01}$

SCALE variable used for scaling plots:

$$
\begin{aligned}
& \text { SCALE }=1 \text { - full scale } \\
& \text { SCALE }=2 \text { - double size } \\
& \text { SCALE }=.5 \text { - one-half scale, etc. }
\end{aligned}
$$

(Because of the limitations of the Calcomp plotter, a maximum of a 5-inch radius can be drawn.)

SS

array for extra masses

STA array for station numbers of bearings and couplings

TAID array for inside diameters of tapered sections

TAOD array for outside diameters of tapered sections

THIC array for thicknesses of disks

\section{DATA INPUT}

All computer runs require a title card, a NAMELIST card, and a set of shaft data cards. The title card is used for problem identification on the printed and plotted output. The NAMELIST card contains all the input parameters and program switches. The shaft data cards contain the physical and geometric properties of the shaft.

Two formats, 300 and 400 , are used to read in the shaft data cards. FORMAT 300 is used for the outside and inside diameters of each shaft section, along with the physical properties of the shaft. FORMAT 400 is used for the cross-sectional areas and the moments of inertia of each shaft section, along with the physical properties of the shaft. See the section Preparation of Shaft Data Cards.

The order in which the title card, NAMELIST card, and shaft data cards enter the computer is illustrated by figure 1 .

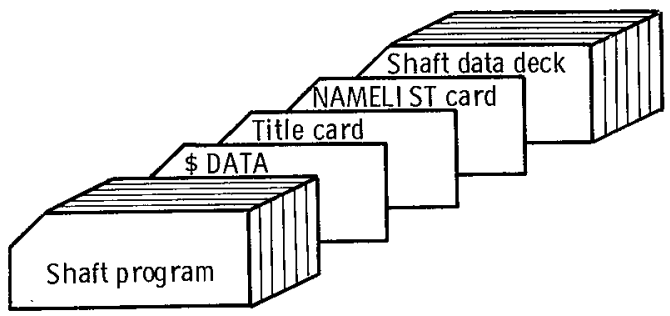

Figure l. - Deck setup. 


\section{Computer Output}

The program produces printed and plotted output. The printed output gives all the input data and the critical speeds. The program will also print the data necessary to plot the rpm-against-excess-moment curve. This option is used to confirm the converged critical speeds and is automatically printed whenever a discontinuity occurs in the excess moment.

The plotted output is not only beneficial for analysis but also for simplicity in recordkeeping. The plotting routine produces a drawing of the shaft with superimposed deflection curves at the critical speed together with all pertinent information related to the shaft. Another form of plotted output is the critical-speed-against-bearing-stiffness plot. For illustrations of the output, see the section Sample Problems with Output.

In addition to the output already described, the program also prints the following error messages:

(1) Inside diameter is greater than outside diameter - shaft data card $* .1$

(2) Outside diameter of disk at station * is equal to or less than zero.

(3) Location of disk is out of range.

(4) Station location is out of range.

(5) No convergence on critical speed occurred after 35 iterations.

\section{Preparation of Shaft Data Cards}

The shaft cards contain the physical and geometric properties of the shaft. The procedure for the preparation of these cards for both tapered and untapered shafts follows:

Shaft without taper. - Figure 2 is a scaled drawing of a multispan shaft system of a two-stage turbine. The system contains four bearings and two couplings. Also, there are eight extra masses ${ }^{2}$ (nonshaft mass) and one disk. To prepare this shaft system for the computer program, the following procedure is used:

Step 1: Vertical lines are drawn perpendicular to the shaft where bearings, couplings, extra masses, and disks are located.

${ }^{1}$ Asterisk denotes station number or card number to be printed by program.

2 The program does not allow for an extra mass, bearing, or disk that is located at the initial end of the shaft $x=0$. To achieve the equivalent, simply make section 0-to-1 small (0.00001) and place the bearing, disk, or extra mass at station 1. 


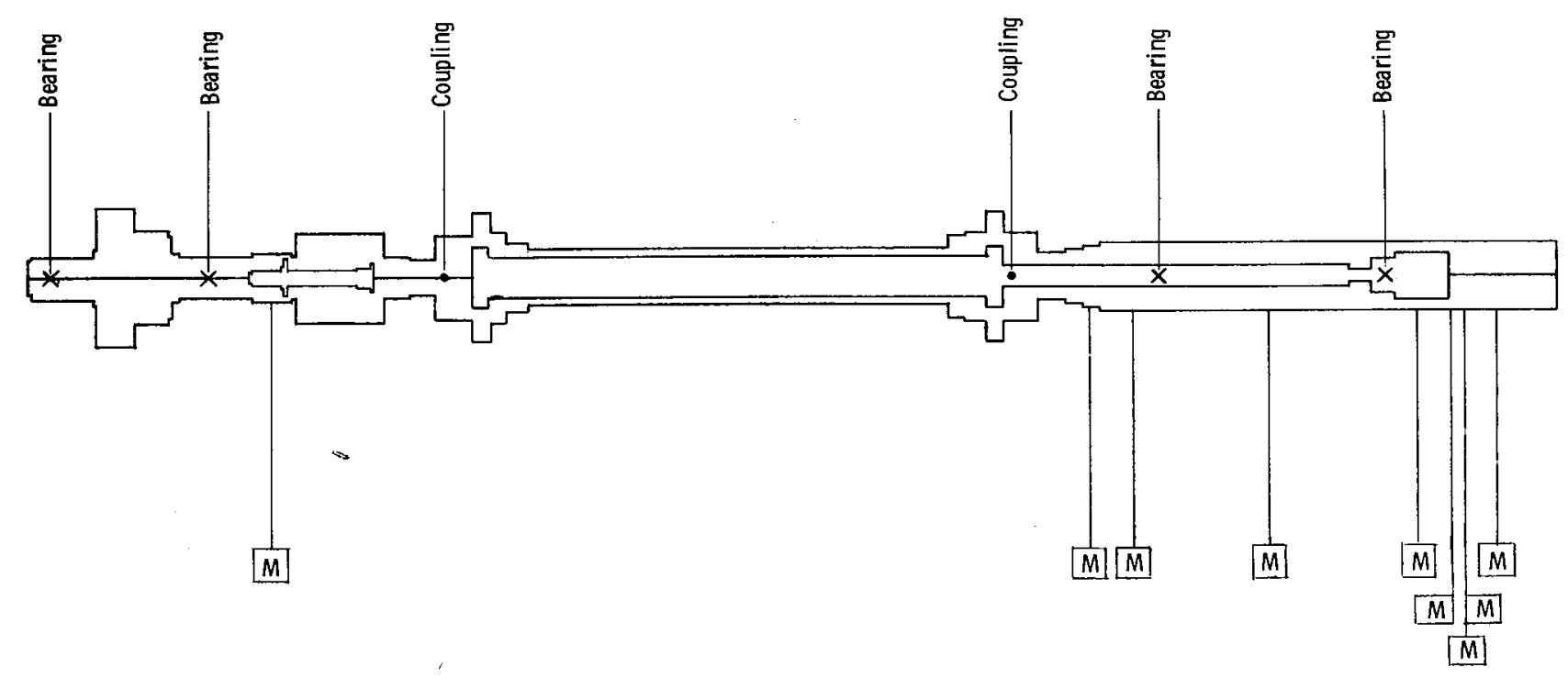

[MI] = Nonshaft mass

Figure 2 - Multispan shaft system for a two-stage turbine (nontapered shaft).

Step 2: Vertical lines are drawn perpendicular to the shaft where a change in every cross section of the shaft occurs, including the points $\mathrm{x}=0$ and $\mathrm{x}=\mathrm{L}$.

Step 3: Starting at the left end of the shaft, number the vertical lines 0 to $n$. The numbered vertical lines represent stations, and the segments between stations are sections. (Figure 3 illustrates this procedure for the first 25 sections of the shaft system of figure 2.)

Step 4: Fill out the shaft data sheet (fig. 4) with the appropriate values for each section and station.

Shaft with taper. - Figure 5 is a scaled drawing of a three-span shaft system of a seven-stage compressor with a tapered portion. The system contains two bearings and 15 extra masses.

For the tapered portion the outside and inside diameters of the left end are placed in columns 6 to 10 and 11 to 15, respectively, of the shaft data sheet (fig. 4). The outside and inside diameters of the right end are placed in columns 26 to 30 and 31 to 35 , respectively. Figure 6 illustrates the procedure for the first 10 sections of the shaft system of figure 5 , and figure 7 is the data sheet.

Blade preparation. - Because of the many variations in blade configurations, no set procedure is presented for the breakdown of a blade for proper input to the computer program.

In general, a blade is broken down into different sections; and each section contains the cross-sectional area, moment of inertia, modulus of elasticity, and mass density. Figure 8 shows a breakdown of a blade, and figure 9 is the blade data sheet. 


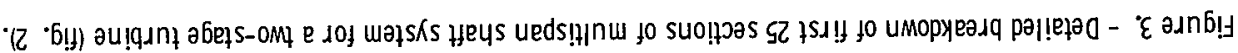

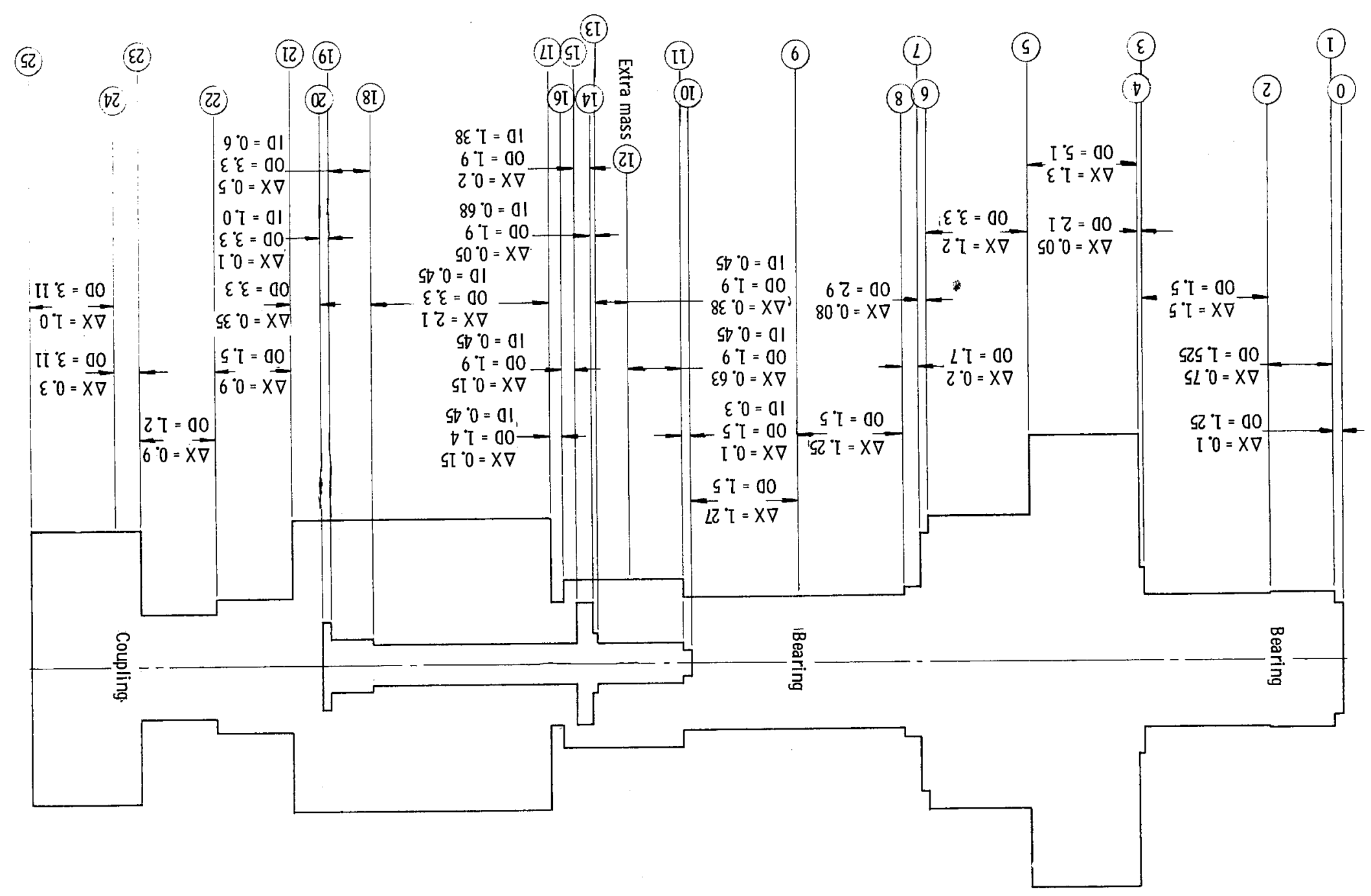


$\stackrel{\infty}{\infty}$

\begin{tabular}{|c|c|c|c|c|c|c|c|c|c|c|c|c|c|c|c|c|c|c|c|c|c|c|c|c|c|c|c|c|c|c|c|c|c|c|c|c|}
\hline \multirow[t]{2}{*}{$\begin{array}{l}\text { Shaft } \\
\text { section }\end{array}$} & \multicolumn{5}{|c|}{$\begin{array}{c}\text { Change in } \\
\text { axial } \\
\text { position, } \\
x, \\
\text { in. } \\
\end{array}$} & \multicolumn{5}{|c|}{$\begin{array}{l}\text { Outside } \\
\text { diameter, } \\
\text { in. }\end{array}$} & \multicolumn{4}{|c|}{$\begin{array}{l}\text { Inside } \\
\text { diameter, } \\
\text { in. }\end{array}$} & \multicolumn{5}{|c|}{$\begin{array}{l}\text { Modulus } \\
\text { of } \\
\text { elasticity, } \\
\text { Ib/in. 2 }\end{array}$} & \multicolumn{4}{|c|}{$\begin{array}{c}\text { Mass } \\
\text { density, } \\
\mid \mathrm{b}-\sec ^{2} / \mathrm{in} .4\end{array}$} & \multicolumn{4}{|c|}{$\begin{array}{l}\text { Tapered } \\
\text { outside } \\
\text { diameter, } \\
\text { in. }\end{array}$} & \multicolumn{4}{|c|}{$\begin{array}{c}\text { Tapered } \\
\text { inside } \\
\text { diameter, } \\
\text { in. }\end{array}$} & \multicolumn{4}{|c|}{$\begin{array}{l}\text { Extra mass, } \\
\text { Ib-sec } 2 / i n .2 \\
\text { at station- }\end{array}$} & \multirow[t]{2}{*}{ Statior } \\
\hline & 1 & 2 & 3 & 4 & 5 & 6 & 7 & 8 & 9 & 10 & 11 & $12]$ & $\begin{array}{ll}3 & 1 \\
\end{array}$ & 15 & 16 & 17 & 18 & 192 & 202 & \begin{tabular}{l|l}
1 & 22 \\
\end{tabular} & 23 & 24 & 25 & 26 & $2 7 \longdiv { 2 }$ & 29 & 30 & 31 & 323 & 334 & 35 & 36 & 37 & \begin{tabular}{l|l}
38 & 39
\end{tabular} & 4 & \\
\hline $0-1$ & & & 1 & & & & 1 & 2 & 5 & & & & & & 2 & 8 & 0 & + & 6 & $\begin{array}{l}7 \\
7\end{array}$ & 3 & - & 5 & & & & & & & & & & & & & 1 \\
\hline $1-2$ & & & 7 & 5 & & & 1 & 5 & 2 & 5 & & & & & & I & & + & & 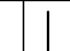 & & - & & & & & & & & & & & & & & 2 \\
\hline $2-3$ & & 1 & 5 & & & & 1 & 5 & & & & & & & & & & + & & & & - & & & & & & & & & & & & & & 3 \\
\hline $3-4$ & & & 0 & 5 & & & 2 & 1 & & & & & & & & & & + & & & & - & & & & & & & & & & & & & & 4 \\
\hline $4-5$ & & 1 & 3 & & & & 5 & 1 & & & & & & & & & & + & & & & - & & & & & & & & & & & & & & 5 \\
\hline $5-6$ & & 1 & 2 & & & & 3 & 3 & & & & & & & & & & + & & & & - & & & & & & & & & & & & & & 6 \\
\hline $6-7$ & & & 0 & 8 & & & 2 & 9 & & & & & & & & & & + & & & & - & & & & & & & & & & & & & & 7 \\
\hline $7-8$ & & & 2 & & & & 1 & 7 & & & & & & & & & & + & & & & - & & & & & & & & & & & & & & 8 \\
\hline $8-9$ & & 1 & 2 & 5 & & & 1 & 5 & & & & & & & & & & + & & & & - & & & & & & & & & & & & & & 9 \\
\hline $9-10$ & & 1 & 2 & 7 & & & 1 & 5 & & & & & & & & & & + & & & & - & & & & & & & & & & & & & & 10 \\
\hline $10-11$ & & & 1 & & & & 1 & 5 & & & & 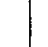 & 3 & & & & & + & & & & - & & & & & & & & & & & & & & 11 \\
\hline $11-12$ & & & 6 & 3 & & & 1 & 9 & & & & . & 4 & & & & & + & & & & - & & & & & & & & & & 0 & 0 & 51 & 1 & 12 \\
\hline $12-13$ & & & 3 & 8 & & & 1 & 9 & & & & 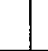 & 4 & & & & & + & & & & - & & & & & & & & & & & & & & 13 \\
\hline $13-14$ & & & 0 & 5 & & & 1 & 9 & & & & & 6 & & & & & + & & & & - & & & & & & & & & & & & & & 14 \\
\hline $14-15$ & & & 2 & 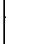 & & & 1 & 9 & & & & 1 & 3 & & & & & + & & & & - & & & & & & & & & & & & & & 15 \\
\hline $15-16$ & & & 1 & 5 & & & 1 & 9 & & & & . & 4 & & & & & + & & & & - & & & & & & & & & & & & & & 16 \\
\hline $16-17$ & & & 1 & 5 & & & 1 & 4 & & & & & 4 & & & & & + & & & & - & & & & & & & & & & & & & & 17 \\
\hline $17-18$ & & 2 & 1 & & & & 3 & 3 & & & & . & 4 & & & & & + & & & & - & & & & & & & & & & & & & & 18 \\
\hline $18-19$ & & & 5 & & & & 3 & 3 & & & & 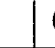 & 6 & & & & & + & & & & - & & & & & & & & & & & & & & 19 \\
\hline $19-20$ & & & 1 & & & & 3 & 3 & & & & 1 & & & & & & + & & & & - & & & & & & & & & & & & & & 20 \\
\hline $20-21$ & & & 3 & 5 & & & 3 & 3 & & & & & & & & & & + & & & & - & & & & & & & & & & & & & & 21 \\
\hline $21-22$ & & & 9 & & & & 1 & 5 & & & & & & & & & & + & & & & - & & & & & & & & & & & & & & 22 \\
\hline $22-23$ & & & 9 & & & & 1 & 2 & & & & & & & & & & + & & 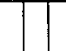 & & - & & & & & & & & & & & & & & 23 \\
\hline $23-24$ & & & 3 & & & & 3 & 1 & 1 & & & & & & & 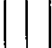 & & + & & 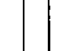 & & - & & & & & & & & & & & & & & 24 \\
\hline $24-25$ & & 1 & & & & & 3 & 1 & 1 & & & & & & & 1 & & + & & 1 & & - & & & & & & & & & & & & & & 25 \\
\hline $25-26$ & & & & & & & & & & & & & & & & & & + & & & & - & & & & & & & & & & & & & & 26 \\
\hline $26-27$ & & & & & & & & & & & & & & & & & & + & & & & - & & & & & & & & & & & & & & 27 \\
\hline $27-28$ & & & & & & & & & & & & & & & & & & + & & & & - & & & & & & & & & & & & & & 28 \\
\hline
\end{tabular}




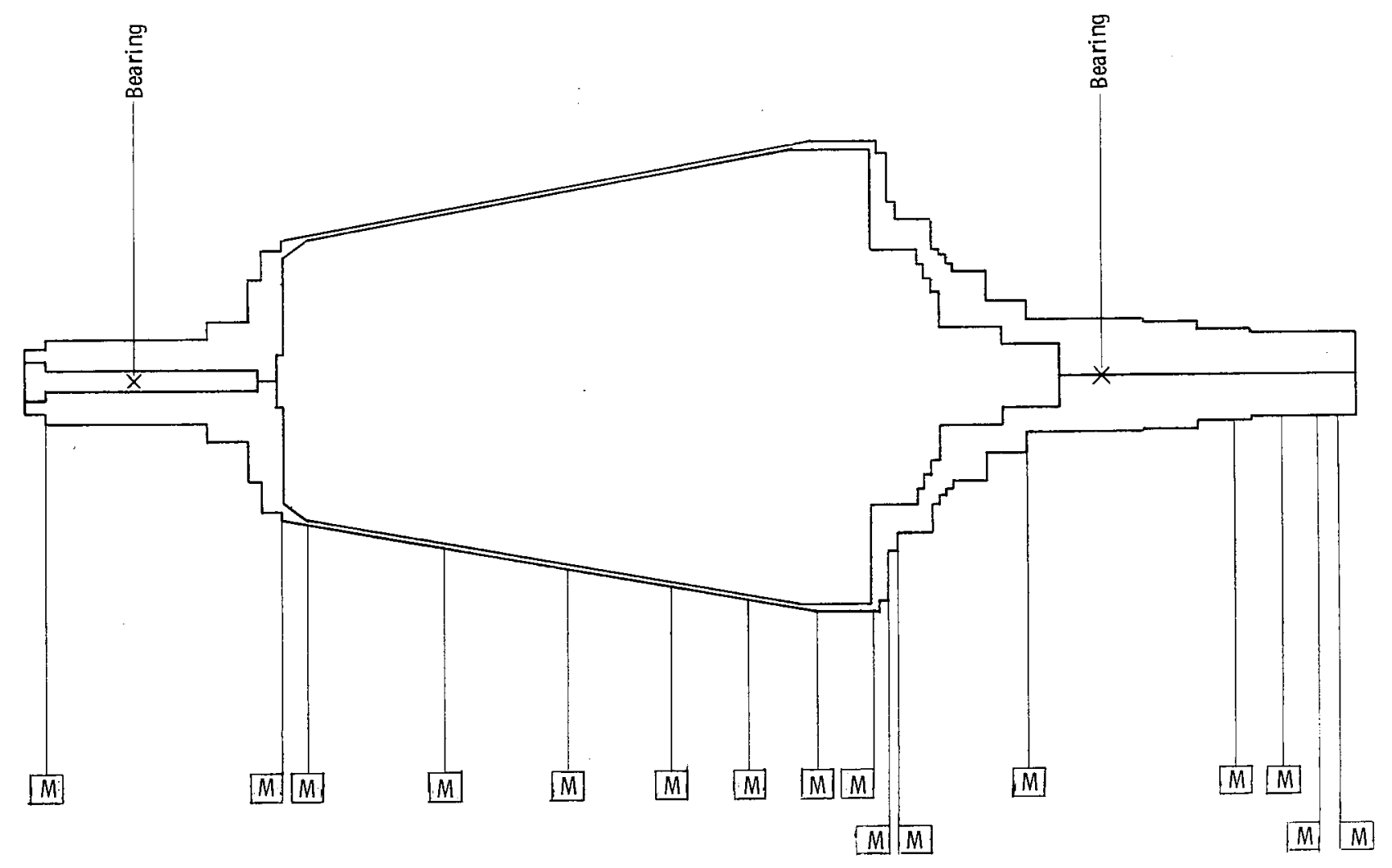

M. Nonshaft mass

Figure 5. - Seven-stage compressor with tapered portion. 


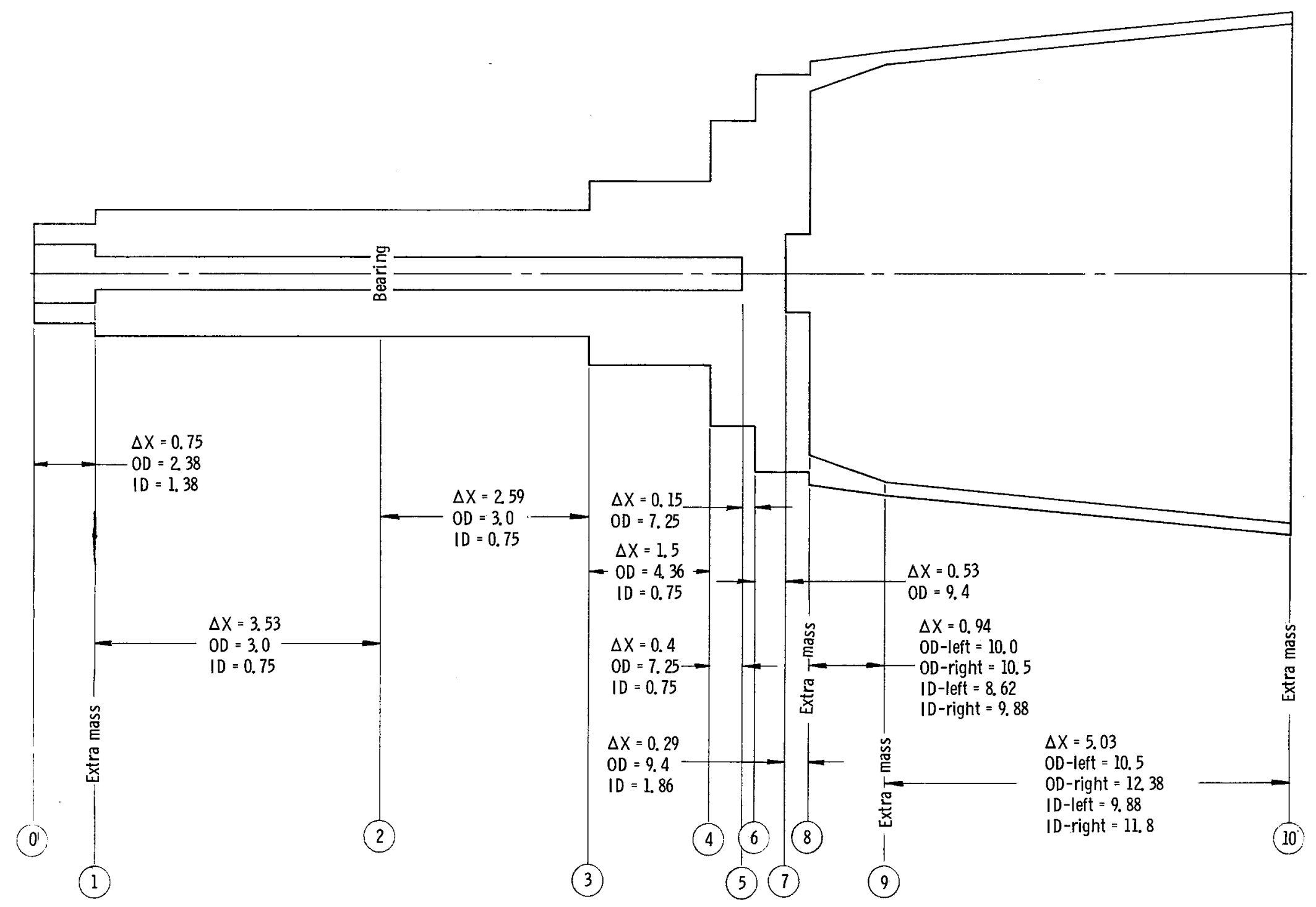

Figure 6. - Detailed breakdown of first 10 sections of seven-stage compressor with tapered portion (fig. 5). 


\begin{tabular}{|c|c|c|c|c|c|c|c|c|c|c|c|c|c|c|c|c|c|c|c|c|c|c|c|c|c|c|c|c|c|c|c|c|c|c|c|c|c|c|c|c|}
\hline \multirow[t]{2}{*}{$\begin{array}{c}\text { Shaft } \\
\text { section }\end{array}$} & \multicolumn{5}{|c|}{$\begin{array}{l}\text { Change in } \\
\text { axial } \\
\text { position, } \\
x \text {, } \\
\text { in. }\end{array}$} & \multicolumn{5}{|c|}{$\begin{array}{l}\text { Outside } \\
\text { diameter, } \\
\text { in. }\end{array}$} & \multicolumn{5}{|c|}{$\begin{array}{l}\text { Inside } \\
\text { diameter, } \\
\text { in. }\end{array}$} & \multicolumn{5}{|c|}{$\begin{array}{l}\text { Modulus } \\
\text { of } \\
\text { elasticity, } \\
\text { lb/in. }\end{array}$} & \multicolumn{5}{|c|}{$\begin{array}{c}\text { Mass } \\
\text { density, } \\
\text { Ib-sec } 2 \text { lin. } 4\end{array}$} & \multicolumn{5}{|c|}{$\begin{array}{c}\text { Tapered } \\
\text { outside } \\
\text { diameter, } \\
\text { in. }\end{array}$} & \multicolumn{5}{|c|}{$\begin{array}{l}\text { Tapered } \\
\text { inside } \\
\text { diameter, } \\
\text { in. }\end{array}$} & \multicolumn{4}{|c|}{$\begin{array}{l}\text { Extra mass } \\
\text { Ib-sec } 2 \text { lin. } 2 \\
\text { at station- }\end{array}$} & \multirow[t]{2}{*}{ Station } \\
\hline & 1 & 2 & 3 & 4 & 5 & 6 & 7 & 8 & 9 & 10 & 11 & 12 & 13 & 14 & 15 & 16 & 17 & 18 & 19 & 20 & 21 & 22 & 23 & 24 & 25 & 26 & 27 & 28 & 29 & 30 & 31 & 32 & 33 & 34 & 35 & 36 & 37 & 38 & 39 & \\
\hline $0-1$ & & & 7 & 5 & & & 2 & 3 & 8 & & & 1 & 3 & 8 & & 2 & 9 & 0 & + & 6 & 7 & 4 & 0 & - & 5 & & & & & & & & & & & 0 & 1 & 4 & 8 & 1 \\
\hline $1-2$ & & 3 & 5 & 3 & & & 3 & & & & & & 7 & 5 & & & 1 & & + & & & 1 & & - & & & & & & & & & & & & & & & & 2 \\
\hline $2-3$ & & 2 & 5 & 9 & & & 3 & & & & & & 7 & 5 & & & & & + & & & & & - & & & & & & & & & & & & & & & & 3 \\
\hline $3-4$ & & 1 & 5 & & & & 4 & 3 & 6 & & & & 7 & 5 & & & & & + & & & & & - & & & & & & & & & & & & & & & & 4 \\
\hline $4-5$ & & & 4 & & & & 7 & 2 & 5 & & & & 7 & 5 & & & & & + & & & & & - & & & & & & & & & & & & & & & & 5 \\
\hline $5-6$ & & & 1 & 5 & & & 7 & 2 & 5 & & & 0 & & & & & & & + & & & & & - & & & & & & & & & & & & & & & & 6 \\
\hline $6-7$ & & & 5 & 3 & & & 9 & 4 & & & & 0 & & & & & & & + & & & & & - & & & & & & & & & & & & & & & & 7 \\
\hline $7-8$ & & & 2 & 9 & & & 9 & 4 & & & & 1 & 8 & 6 & & & & & + & & & & & - & & & & & & & & & & & & 0 & 1 & 5 & 5 & 8 \\
\hline $8-9$ & & & 9 & 4 & & 1 & 0 & 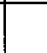 & & & & 8 & 6 & 2 & & & 1 & & + & & & 1 & & - & & 1 & 0 & 5 & & & & 9 & 8 & 8 & & 0 & 7 & 6 & 8 & 9 \\
\hline $9-10$ & & 5 & 0 & 3 & & 1 & 0 & 5 & & & & 9 & 8 & 8 & & & 1 & & + & & & 7 & & - & & 1 & 2 & 3 & 8 & & 1 & 1 & 8 & & & 1 & I & 3 & 9 & 10 \\
\hline $10-11$ & & & & & & & & & & & & & & & & & & & + & & & & & - & & & & & & & & & & & & & & & & 11 \\
\hline $11-12$ & & & & & & & & & & & & & & & & & & & + & & & & & - & & & & & & & & & & & & & & & & 12 \\
\hline $12-13$ & & & & & & & & & & & & & & & & & & & + & & & & & - & & & & & & & & & & & & & & & & 13 \\
\hline $13-14$ & & & & & & & & & & & & & & & & & & & + & & & & & - & & & & & & & & & & & & & & & & 14 \\
\hline $14-15$ & & & & & & & & & & & & & & & & & & & + & & & & & - & & & & & & & & & & & & & & & & 15 \\
\hline $15-16$ & & & & & & & & & & & & & & & & & & & + & & & & & - & & & & & & & & & & & & & & & & 16 \\
\hline $16-17$ & & & & & & & & & & & & & & & & & & & + & & & & & - & & & & & & & & & & & & & & & & 17 \\
\hline $17-18$ & & & & & & & & & & & & & & & & & & & + & & & & & - & & & & & & & & & & & & & & & & 18 \\
\hline $18-19$ & & & & & & & & & & & & & & & & & & & + & & & & & - & & & & & & & & & & & & & & & & 19 \\
\hline $19-20$ & & & & & & & & & & & & & & & & & & & + & & & & & - & & & & & & & & & & & & & & & & 20 \\
\hline $20-21$ & & & & & & & & & & & & & & & & & & & + & & & & & - & & & & & & & & & & & & & & & & 21 \\
\hline $21-22$ & & & & & & & & & & & & & & & & & & & + & & & & & $\overline{-}$ & & & & & & & & & & & & & & & & 22 \\
\hline $22-23$ & & & & & & & & & & & & & & & & & & & + & & & & & - & & & & & & & & & & & & & & & & 23 \\
\hline $23-24$ & & & & & & & & & & & & & & & & & & & + & & & & & - & & & & & & & & & & & & & & & & 24 \\
\hline 24-25 & & & & & & & & & & & & & & & & & & & + & & & & & - & & & & & & & & & & & & & & & & 25 \\
\hline $25-26$ & & & & & & & & & & & & & & & & & & & + & & & & & - & & & & & & & & & & & & & & & & 26 \\
\hline $26-27$ & & & & & & & & & & & & & & & & & & & + & & & & & - & & & & & & & & & & & & & & & & 27 \\
\hline $27-28$ & & & & & & & & & & & & & & & & & & & + & & & & & - & & & & & & & & & & & & & & & & 28 \\
\hline
\end{tabular}




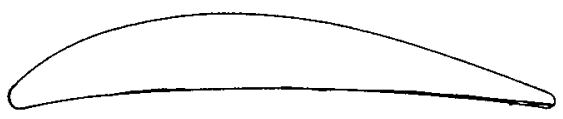

Typical blade profile

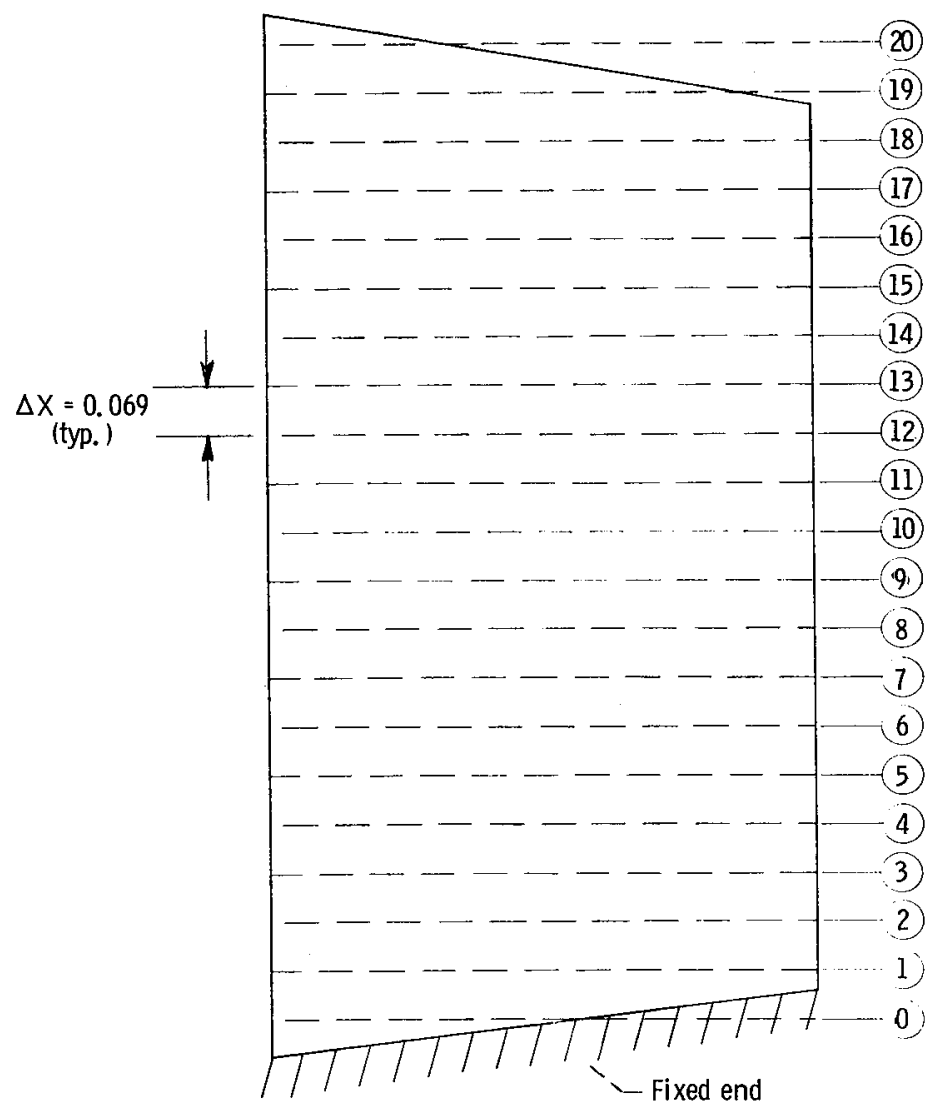

Figure 8. - Breakdown of a compressor blade. 


\begin{tabular}{|c|c|c|c|c|c|c|c|c|c|c|c|c|c|c|c|c|c|c|c|c|c|c|c|c|c|c|c|c|c|c|c|c|c|c|}
\hline \multirow{2}{*}{$\begin{array}{c}\text { Blade } \\
\text { section }\end{array}$} & \multicolumn{6}{|c|}{$\begin{array}{c}\text { Change in } \\
\text { axial } \\
\text { position, } \\
x_{1} \\
\text { in. }\end{array}$} & \multicolumn{7}{|c|}{$\begin{array}{l}\text { Area, } \\
\text { in. }\end{array}$} & \multicolumn{8}{|c|}{$\begin{array}{l}\text { Moment of } \\
\text { inertia, } \\
\text { in. }{ }^{4}\end{array}$} & \multicolumn{4}{|c|}{$\begin{array}{c}\text { Modulus } \\
\text { of } \\
\text { elasticity, } \\
E_{1} \\
\text { Iblin. }{ }^{2}\end{array}$} & \multicolumn{4}{|c|}{$\begin{array}{c}\text { Mass } \\
\text { density, } \\
\text { Ib-sec }^{2} / \mathrm{in} .\end{array}$} & \multicolumn{4}{|c|}{$\begin{array}{l}\text { Extra mass } \\
\text { Ib-sec } \\
\text { at station. } \\
\text { at }\end{array}$} & \multirow[t]{2}{*}{ Station } \\
\hline & 1 & 2 & 3 & 4 & 5 & 6 & 7 & 3 & $\begin{array}{l}9 \\
9\end{array}$ & 11 & 12 & 13 & \begin{tabular}{l|l}
14 & 1 \\
\end{tabular} & 16 & 17 & 18 & 19 & \begin{tabular}{l|l}
20 & 2 \\
\end{tabular} & 22 & 23 & 24 & 25 & $2 6 \longdiv { 2 }$ & $27 \quad 28$ & 29 & 303 & 3132 & 33 & 34 & \begin{tabular}{l|l}
35 & 36 \\
\end{tabular} & \begin{tabular}{l|l|}
6 & 37 \\
\end{tabular} & 38 & 3940 & \\
\hline $0-1$ & & 0 & 6 & 9 & & & & 2 & $\begin{array}{ll}4 & 9\end{array}$ & & & & - & 1 & & 1 & 7 & 8 & & - & 4 & 2 & 7 & $5+$ & 6 & 7 & \begin{tabular}{l|l}
5 & 0 \\
\end{tabular} & $1-$ & 5 & & & & & 1 \\
\hline $1-2$ & & & & & & & & 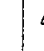 & 47 & 7 & & & - & & & 1 & 6 & 1 & & - & 4 & & & + & & & & - & & & & & & 2 \\
\hline $2-3$ & & & & & & & & 2 & $\begin{array}{l}46 \\
\end{array}$ & 5 & & & - & & & 1 & 4 & \begin{tabular}{l|l}
7 \\
\end{tabular} & & - & 4 & & & + & & & & - & & & & & & 3 \\
\hline $3-4$ & & & & & & & & 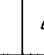 & $\begin{array}{l}45 \\
\end{array}$ & 2 & & & - & & & 1 & 3 & 4 & & - & 4 & & & + & & & & - & & & & & & 4 \\
\hline $4-5$ & & & & & & & & 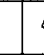 & \begin{tabular}{l|l}
4 & 4 \\
\end{tabular} & 0 & & & - & & & 1 & 2 & 3 & & - & 4 & & & + & & & & - & & & & & & 5 \\
\hline $5-6$ & & & & & & & & 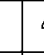 & \begin{tabular}{l|l}
4 & 8 \\
\end{tabular} & 8 & & & - & & & 1 & 1 & 3 & & - & 4 & & & + & & & & - & & & & & & 6 \\
\hline $6-7$ & & & & & & & & 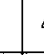 & $\begin{array}{l}4 \\
4\end{array}$ & 7 & & & - & & & 1 & 0 & 4 & & - & 4 & & & + & & & & - & & & & & & 7 \\
\hline $7-8$ & & & & & & & & 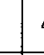 & $\begin{array}{l}4 \\
4\end{array}$ & 4 & & & - & & & 9 & 5 & 1 & & - & 5 & & & + & & & & -1 & & & & & & 8 \\
\hline 8-9 & & & & & & & & 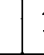 & $\begin{array}{l}3 \\
\end{array}$ & 1 & & & - & & & 8 & 6 & 4 & & - & 5 & & & + & & & & - & & & & & & 9 \\
\hline $9-10$ & & & & & & & & 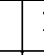 & $\begin{array}{ll}3 & 7 \\
\end{array}$ & 8 & & & - & & & 7 & 8 & & & - & 5 & & & + & & & & - & & & & & & 10 \\
\hline 10-11 & & & & & & & & , & $\begin{array}{l}3 \\
3\end{array}$ & 5 & & & - & & & 7 & 0 & 1 & & - & 5 & & & + & & & & - & & & & & & II \\
\hline $11-12$ & & & & & & & & 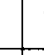 & $\begin{array}{ll}3 & 5 \\
\end{array}$ & 3 & & & - & & & 6 & 3 & & & - & 5 & & & + & & & & - & & & & & & 12 \\
\hline $12-13$ & & & & & & & & 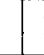 & $\begin{array}{ll}3 & 4 \\
\end{array}$ & 0 & & & - & & & 5 & 6 & 4 & & - & 5 & & & + & & & & - & & & & & & 13 \\
\hline $13-14$ & & & & & & & & 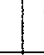 & $\begin{array}{ll}3 & 2 \\
\end{array}$ & 7 & & & - & & & 5 & 0 & 3 & & - & 5 & & & + & & & & - & & & & & & 14 \\
\hline $14-15$ & & & & & & & & 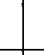 & \begin{tabular}{ll|}
3 & 1 \\
\end{tabular} & 3 & & & - & & & 4. & 4 & 6 & & - & 5 & & & + & & & & - & & & & & & 15 \\
\hline $15-16$ & & & & & & & & 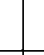 & 3 & & & & - & & & 3 & 9 & 2 & & - & 5 & & & + & & & & - & & & & & & 16 \\
\hline $16-17$ & & & & & & & & - & \begin{tabular}{l|l}
2 & 8 \\
\end{tabular} & $\begin{array}{ll}6 \\
\end{array}$ & & & - & & & 3 & 4 & 2 & & - & 5 & & & + & & & & - & & & & & & 17 \\
\hline $17-18$ & & & & & & & & 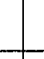 & $\begin{array}{ll}27 \\
\end{array}$ & 2 & & & - & & & 2 & 9 & 6 & & - & 5 & & & + & & & & - & & & & & & 18 \\
\hline $18-19$ & & & 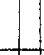 & & & & & 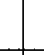 & \begin{tabular}{|l|l}
2 & 5 \\
\end{tabular} & 9 & & & - & & & 2 & 5 & 9 & & - & 5 & & & + & & & & - & & & & & & 19 \\
\hline $19-20$ & & & 1 & & & & & 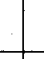 & $\begin{array}{ll}2 & 4 \\
\end{array}$ & $\begin{array}{l}78 \\
\end{array}$ & & & - & & & 2 & 3 & 2 & & - & 5 & & 1 & + & & & 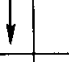 & - & & & & & & 20 \\
\hline $20-21$ & & & & & & & & & & & & & - & & & & & & & - & & & & + & & & & - & & & & & & 21 \\
\hline $21-22$ & & & & & & & & & & & & & - & & & & & & & - & & & & + & & & & - & & & & & & 22 \\
\hline $22-23$ & & & & & & & & & & & & & - & & & & & & & - & & & & + & & & & - & & & & & & 23 \\
\hline $23-24$ & & & & & & & & & & & & & - & & & & & & & - & & & & + & & & & - & & & & & & 24 \\
\hline $24-25$ & & & & & & & & & & & & & - & & & & & & & - & & & & + & & & & - & & & & & & 25 \\
\hline $25-26$ & & & & & & & & & & & & & - & & & & & & & - & & & & + & & & & - & & & & & & 26 \\
\hline $26-27$ & & & & & & & & & & & & & - & & & & & & & - & & & & + & & & & - & & & & & & 27 \\
\hline $27-28$ & & & & & & & & & & & & & - & & & & & & & $\cdot$ & & & & + & & & & - & & & & & & 28 \\
\hline
\end{tabular}




\section{Sample Problems with Output}

The purpose of this section is twofold: (1) to show the flexibility of the program, and (2) to illustrate specifically the preparation of the NAMELIST card for particular problems. The following six problems will be considered:

(1) Multispan shaft with bearings and couplings, as well as a disk for the gyroscopic effect, and extra masses

(2) Successive cases using same shaft data but different bearing constants

(3) Problem 1 with modified shaft data

(4) Free-free, single-span shaft

(5) Set of cases to produce bearing-stiffness-against-critical-speed plot

(6) Blade calculation with fixed-end boundary condition (cantilever beam and nonrotating uncoupled bending vibration)

The program has built-in standard options; and consequently, they need not be placed on the NAMELIST card when a specific case is run. These standard options are indicated by an underscore in the section FORTRAN Symbols for NAMELIST Card. For example, ICM=0 is underscored and therefore indicates that a plot will always be part of the output. If, however, no plot is desired, ICM=1 must be put on the NAMELIST card for the specific problem being run.

Problem 1 - multispan shaft. - The NAMELIST card described here contains the proper variables and constants that will enable the program to compute a critical speed for the shaft system in figure 2. The procedure for problem 1 is as follows:

Title card

NAMELIST card

Shaft data cards

where

$\mathrm{L}=51$

$\mathrm{KB}=6$

SCALE $=.25$

$\mathrm{ST} \mathrm{A}=2,9,24,34,41,45$

\section{TWO-STAGE TURBINE}

\$SHAFT $\mathrm{L}=51, \mathrm{~KB}=6$, SCALE $=.25, \mathrm{STA}=2,9,24,34,41,45$, $\mathrm{BRG}=2 * 50 . \mathrm{E}+03,2 *-1,500 . \mathrm{E}+03,100 . \mathrm{E}+03, \mathrm{ISK}=1, \mathrm{ND}=1$, $\mathrm{KL}=1, \mathrm{~A}=.80994, \mathrm{BB}=.79379, \mathrm{LOC}=50 \$$

obtained from shaft system (fig. 2)

number of shaft sections

total number of bearings and couplings

number used for scaling plots

station numbers of bearings and couplings

$\operatorname{STA}(1)=2$

$\operatorname{STA}(2)=9$ 


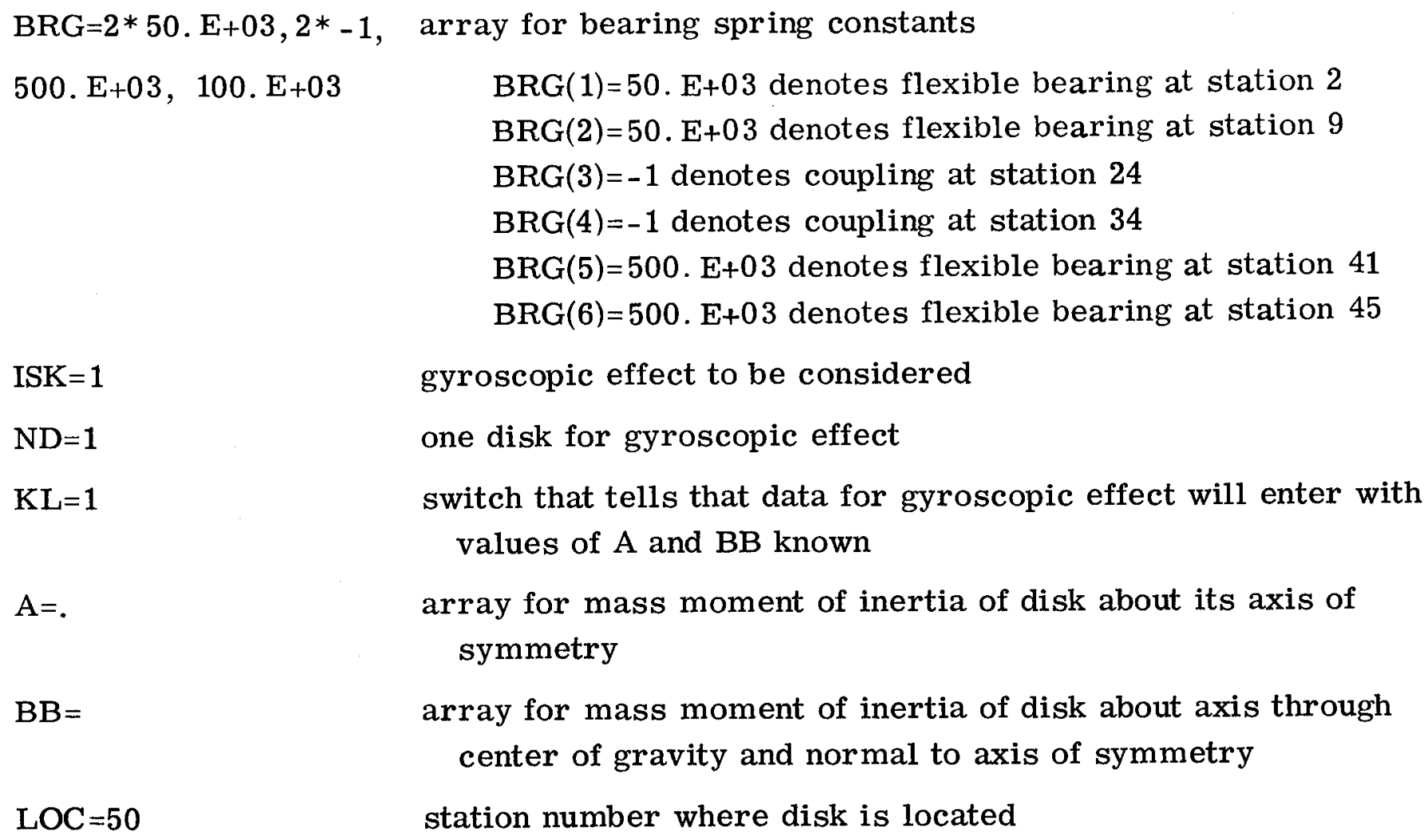

The following variables and constants need not be placed on the NAMELIST card because they are set by the computer program: DRPM, ICM, IC, RPM, RPMF, IH, and KA. If the program is to compute the values of $A$ and $B B$, the NAMELIST card should be

$$
\begin{aligned}
& \text { \$SHAFT } \mathrm{L}=51, \mathrm{~KB}=6, \mathrm{SCALE}=.25, \mathrm{STA}=2,9,24,34,41,45, \\
& \mathrm{BRG}=2 * 5 . \mathrm{E}+04,2 *-1,5 . \mathrm{E}+05,1 . \mathrm{E}+05, \mathrm{ISK}=1, \mathrm{ND}=1, \mathrm{LOC}=50, \\
& \text { ODIA=5. 5, } \mathrm{DEN}=.266 \mathrm{E} 03, \mathrm{DIA}=0, \mathrm{THIC}=1.5 \$
\end{aligned}
$$

where ODIA, DIA, THIC, and DEN are the outside and inside diameters, the thickness, and the mass density of the disk.

Figures 10 and 11 are the printed and computer -plotted output of problem 1 . Figure 12 is a hand-drawn plot of excess moment as a function of rpm, for problem 1 . 


\begin{tabular}{|c|c|c|c|c|c|c|c|}
\hline $\begin{array}{l}x \\
0.1000 \\
c .7500 \\
1.5000 \\
c .0500 \\
1.3000 \\
1.2000 \\
0.0000 \\
0.2000 \\
1.2500 \\
1.2700 \\
0.1000 \\
0.6300 \\
0.3800 \\
0.0500 \\
0.2000 \\
0.1500 \\
0.1500 \\
2.1000 \\
0.5000 \\
0.1000 \\
0.3500 \\
6.9000 \\
0.9000 \\
0.3000 \\
1.0000 \\
0.6500 \\
0.5100 \\
0.7900 \\
14.5000 \\
0.1700 \\
0.5200 \\
0.7400 \\
0.6000 \\
0.4900 \\
0.7500 \\
1.0200 \\
0.6000 \\
0.2800 \\
0.2800 \\
1.1800 \\
0.6600 \\
4.1000 \\
2.6800 \\
0.8600 \\
0.6300 \\
0.2000 \\
0.6600 \\
1.2500 \\
0.4000 \\
1.1400 \\
2.2200\end{array}$ & $\begin{array}{l}00 \\
1.2500 \\
1.5250 \\
1.5000 \\
2.1000 \\
5.1000 \\
3.3000 \\
2.9000 \\
1.7000 \\
1.5000 \\
1.5000 \\
1.5000 \\
1.9000 \\
1.9000 \\
1.9000 \\
1.9000 \\
1.9000 \\
1.4000 \\
3.3000 \\
3.3000 \\
3.3000 \\
3.3000 \\
1.5000 \\
1.2000 \\
3.1100 \\
3.1100 \\
4.7500 \\
3.1800 \\
2.4000 \\
2.0000 \\
2.0000 \\
3.0000 \\
3.1900 \\
4.7500 \\
3.1000 \\
3.1000 \\
1.5600 \\
2.0000 \\
2.1500 \\
2.1500 \\
2.5000 \\
2.5000 \\
2.5000 \\
2.5000 \\
2.5000 \\
2.5000 \\
2.5000 \\
2.5000 \\
2.5000 \\
2.5000 \\
2.5000 \\
2.5000 \\
\end{array}$ & $\begin{array}{l}10 \\
-0 . \\
-0 . \\
-0 . \\
-0 . \\
-0 . \\
-0 . \\
-0 . \\
-0 . \\
-0 . \\
-0 . \\
0.3000 \\
0.4500 \\
0.4500 \\
0.6800 \\
1.3800 \\
0.4500 \\
0.4500 \\
0.4500 \\
0.6000 \\
1.0000 \\
-0.0 \\
-0 . \\
-0 . \\
-0 . \\
-0 . \\
2.2200 \\
1.3600 \\
1.3600 \\
1.3600 \\
1.3600 \\
1.3600 \\
1.3600 \\
2.3500 \\
0.8800 \\
0.8800 \\
0.8800 \\
0.88600 \\
0.8800 \\
0.8800 \\
0.8800 \\
0.8800 \\
0.8800 \\
0.8800 \\
0.5000 \\
1.3100 \\
1.33100 \\
1.6600 \\
1.6600 \\
-0.0 \\
-0 . \\
-0 .\end{array}$ & $\begin{array}{l}\text { EW } \\
-0 . \\
-0 . \\
-0 . \\
-0 . \\
-0 . \\
-0 . \\
-0 . \\
-0 . \\
-0 . \\
-0 . \\
-0 . \\
0.005060 \\
-0 . \\
-0 . \\
-0 . \\
-0 . \\
-0 . \\
-0 . \\
-0 . \\
-0 . \\
-0 . \\
-0 . \\
-0 . \\
-0 . \\
-0 . \\
-0 . \\
-0 . \\
-0 . \\
-0 . \\
-0 . \\
-0 . \\
-0 . \\
-0 . \\
-0 . \\
-0 . \\
-0 . \\
-0 . \\
0.001400 \\
-0.0 \\
0.000643 \\
-0.000908 \\
0.000908 \\
-0.0 \\
-0 . \\
-0 . \\
-0 . \\
0.000643 \\
0.004300 \\
0.015000 \\
0.013700 \\
-0 .\end{array}$ & $\begin{array}{r}E \\
0.28000 E+08 \\
0.28000 E+08 \\
0.28000 E+08 \\
0.28000 E+08 \\
0.26000 E+08 \\
0.28000 E+08 \\
0.28000 E+08 \\
0.28000 E+08 \\
0.28000 E+08 \\
0.280000+08 \\
0.28000 E+08 \\
0.28000 E+08 \\
0.280000 E+08 \\
0.28000 E+08 \\
0.28000 E+08 \\
0.10000 E+08 \\
0.100000 E+08 \\
0.10000 E+08 \\
0.10000 E+08 \\
0.28000 E+08 \\
0.28000 E+08 \\
0.28000 E+08 \\
0.28000 E+08 \\
0.28000 E+08 \\
0.28000 E+08 \\
0.28000 E+08 \\
0.28000 E+08 \\
0.28000 E+08 \\
0.28000 E+08 \\
0.28000 E+08 \\
0.28000 E+08 \\
0.28000 E+08 \\
0.28000 E+08 \\
0.28000 E+08 \\
0.28000 E+08 \\
0.28000 E+08 \\
0.28000 E+08 \\
0.28000 E+08 \\
0.28000 E+08 \\
0.28000 E+08 \\
0.28000 E+08 \\
0.28000 E+08 \\
0.28000 E+08 \\
0.28000 E+08 \\
0.28000 E+08 \\
0.28000 E+08 \\
0.28000 E+08 \\
0.28000 E+08 \\
0.28000 E+08 \\
0.28000 E+08 \\
0.28000 E+08\end{array}$ & $\begin{array}{l}\text { RHO } \\
0.73300 E-03 \\
0.73300 E-03 \\
0.73300 E-03 \\
0.73300 E-03 \\
0.73300 E-03 \\
0.73300 E-03 \\
0.73300 E-03 \\
0.73300 E-03 \\
0.73300 E-03 \\
0.73300 E-03 \\
0.73300 E-03 \\
0.73300 E-03 \\
0.73300 E-03 \\
0.73300 E-03 \\
0.73300 E-03 \\
0.25900 E-03 \\
0.25900 E-03 \\
0.25900 E-03 \\
0.25900 E-03 \\
0.73300 E-03 \\
0.73300 E-03 \\
0.73300 E-03 \\
0.73300 E-03 \\
0.73300 E-03 \\
0.73300 E-03 \\
0.73300 E-03 \\
0.73300 E-03 \\
0.73300 E-03 \\
0.73300 E-03 \\
0.73300 E-03 \\
0.73300 E-03 \\
0.73300 E-03 \\
0.73300 E-03 \\
0.73300 E-03 \\
0.73300 E-03 \\
0.73300 E-03 \\
0.73300 E-03 \\
0.73300 E-03 \\
0.73300 E-03 \\
0.73300 E-03 \\
0.73300 E-03 \\
0.73300 E-03 \\
0.73300 E-03 \\
0.73300 E-03 \\
0.73300 E-03 \\
0.73300 E-03 \\
0.73300 E-03 \\
0.733000 E-03 \\
0.73300 E-03 \\
0.73300 E-03 \\
0.73300 E-03\end{array}$ & $\begin{array}{l}\text { TAOD } \\
-0 . \\
-0 . \\
-0 . \\
-0 . \\
-0 . \\
-0 . \\
-0 . \\
-0 . \\
-0 . \\
-0 . \\
-0 . \\
-0 . \\
-0 . \\
-0 . \\
-0 . \\
-0 . \\
-0 . \\
-0 . \\
-0 . \\
-0 . \\
-0 . \\
-0 . \\
-0 . \\
-0 . \\
-0 . \\
-0 . \\
-0 . \\
-0 . \\
-0 . \\
-0 . \\
-0 . \\
-0 . \\
-0 . \\
-0 . \\
-0 . \\
-0 . \\
-0 . \\
-0 . \\
-0 . \\
-0 . \\
-0 . \\
-0 . \\
-0 . \\
-0 . \\
-0 . \\
-0 . \\
-0 . \\
-0 . \\
-0 . \\
-0 . \\
-0 .\end{array}$ & 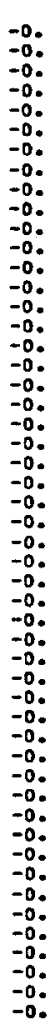 \\
\hline
\end{tabular}

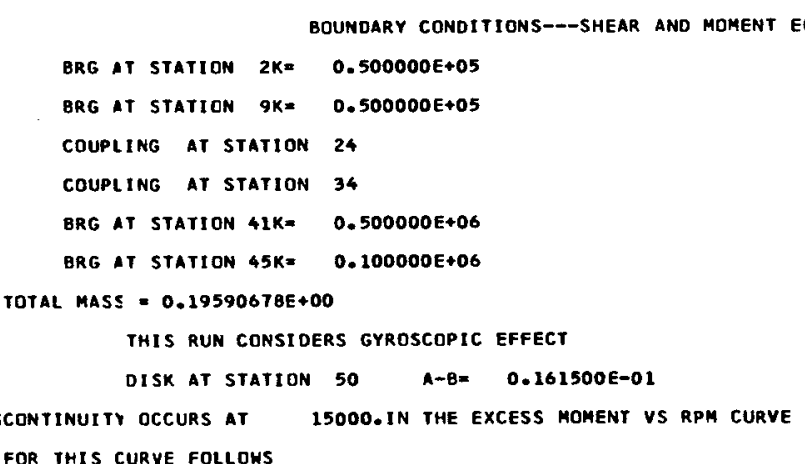

DATA FOR IHIS CURYE FOLLOWS

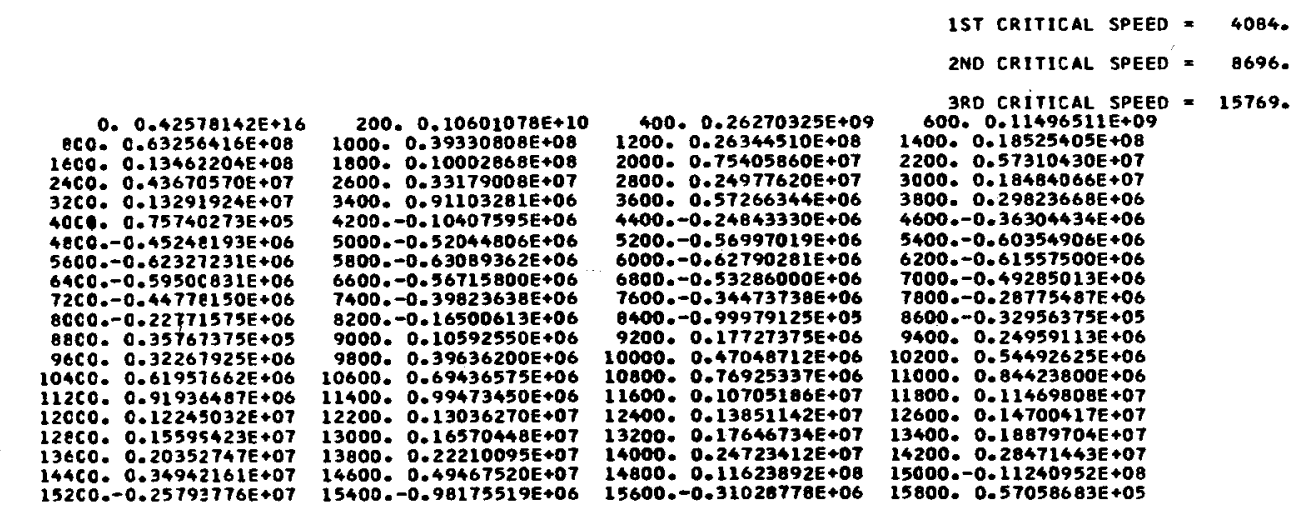

Figure 10. - Printed output for problem 1 (multispan shaft with bearings and couplings, as well as a disk for the gyroscopic effect, and extra masses). 


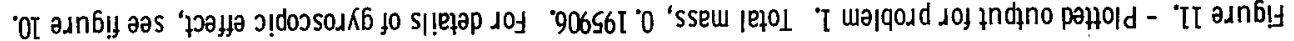

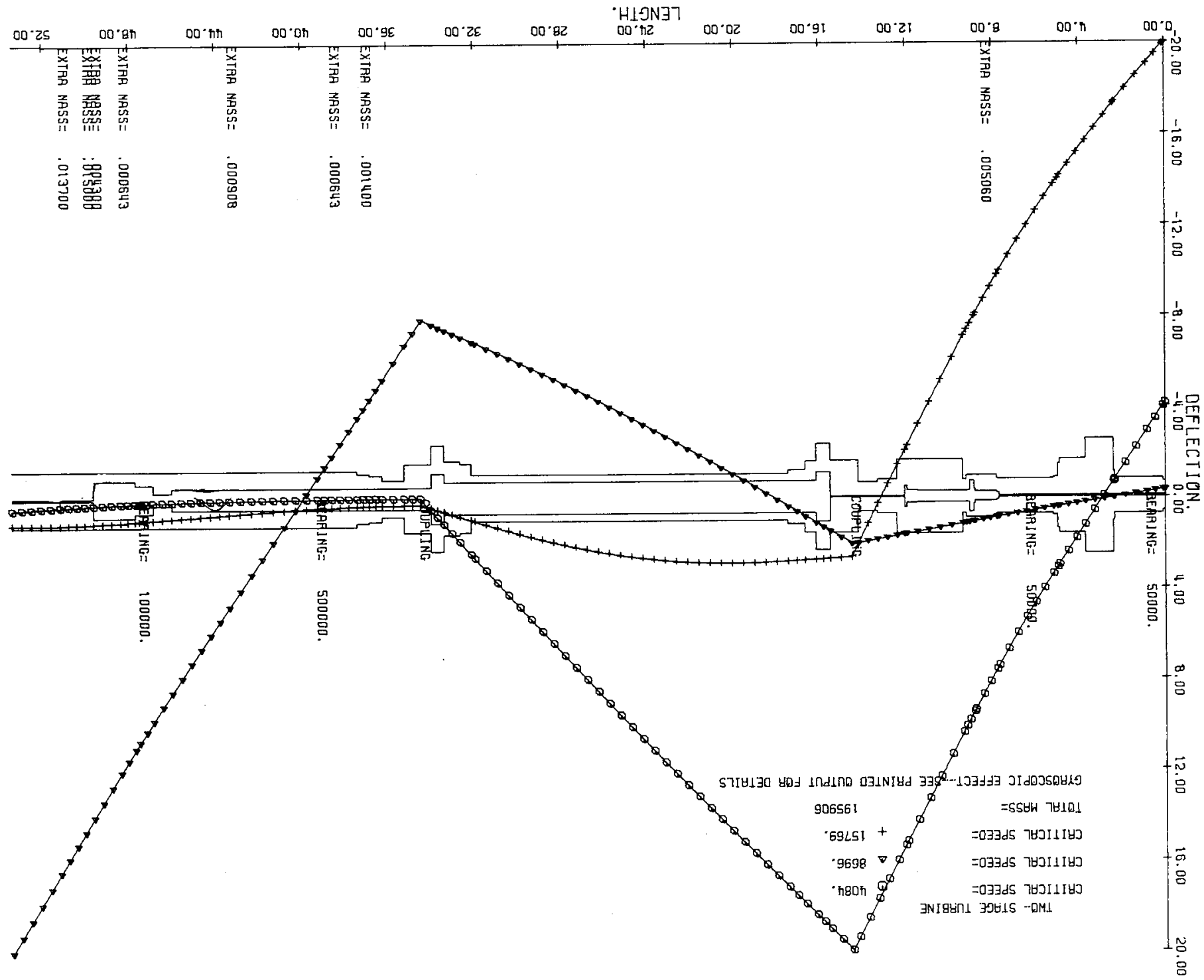




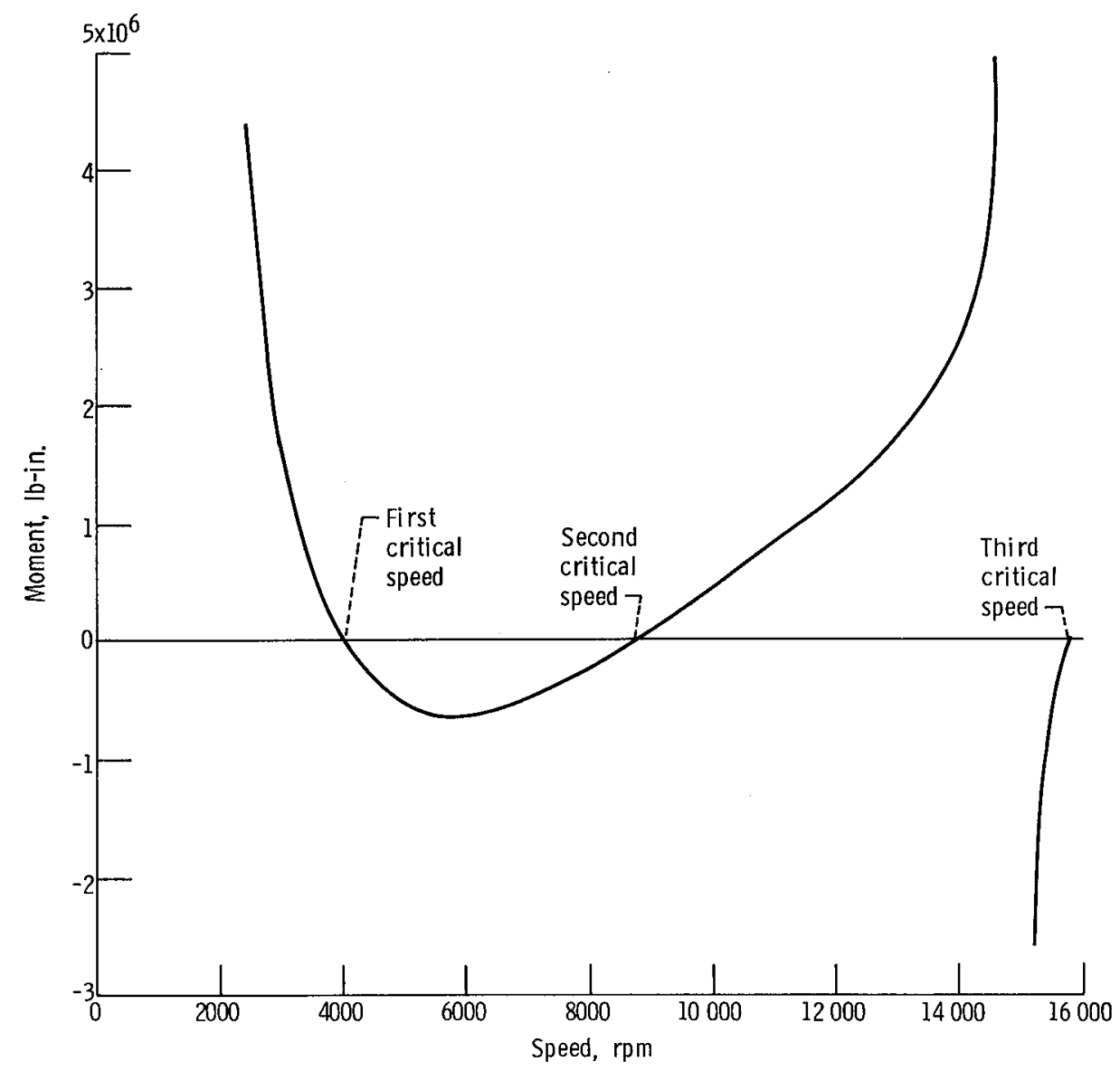

Figure 12. - Hand-drawn plot of excess moment as function of rpm, for problem 1.

Problem 2 - successive cases using same shaft data. - The procedure for problem 2 is as follows:

For case 1:

Title card

NAMELIST card

Shaft data cards

For case 2:

Title card

NAMELIST card

where

$\mathrm{IH}=0$

ISK $=2$ same as for problem 1

same as for problem 1

same as for problem 1

TWO-STAGE TURBINE BRG AT STA2=6. E+06

$\$$ SHAFT IH $=0, \operatorname{SCALE}=.25, \mathrm{ISK}=2, \mathrm{BRG}(1)=6 . \mathrm{E}+06 \$$

switch that indicates shaft data are in computer

switch that indicates gyroscopic data are in computer 

unchanged)

Problem 3 - problem 1 with modified shaft data. - A change from 2.5 inches to 3. 0 inches will be made on the outside diameter for sections 39-40 and 50-51 inclusive. The procedure for problem 3 is as follows:

Title card

NAMELIST card

Shaft data cards

Title card

NAMELIST card

$\mathrm{OD}(40)=12 * 3$.
TWO-STAGE TURBINE - ORIGINAL DATA

\$SHAFT $\mathrm{L}=51, \mathrm{MOD}=1 \$$

Same as for problem 1, where MOD=1 is the switch that returns flow of program to beginning, after shaft data cards are read

TWO-STAGE TURBINE - MODIFIED SHAFT DATA

Same as for problem 1 , plus $\mathrm{IH}=0, \mathrm{OD}(40)=12 * 3 . \$$

outside diameter of 3 inches for 12 consecutive sections starting at section $39-40$

Problem 4 - free-free, single-span shaft. - The procedure for problem 4 is as follows:

Title card

TWO STAGE TURBINE - NO BEARINGS OR COUPLINGS

NAMELIST card

$\$ S H A F T ~ L=51, K B=0, \operatorname{SCALE}=.25 \$$

Shaft data cards

Same as for problem 1

Problem 5 - bearing-stiffness-against-critical-speed plot. - The NAMELIST cards for this problem illustrate the ability of the program to produce a bearing-stiffnessagainst-critical-speed plot. This plot requires six computer runs that use the same shaft data cards. The scale on the $\mathrm{x}$-axis of this plot is determined by changing the spring constant of the same bearing for each run. The first computer run has the smallest bearing constant, the second has the next larger, and so forth. The data used for these runs represent the shaft system of figure 5 .

Case 1:

Title card

NAMELIST card

Shaft data cards
SEVEN-ST AGE COMPRESSOR - CASE 1

\$SHAFT L $=39, \mathrm{STA}=2,31, \mathrm{BRG}=2 * 300 . \mathrm{E}+03, \mathrm{SCALE}=.25$, $\mathrm{KB}=\mathbf{2} \$$

obtained from shaft system of figure 2 
Case 2:

Title card

NAMELIST card

Case 3:

Title card

NAMELIST card

Case 4:

Title card

NAMELIST card

Case 5:

Title card

NAMELIST card
CASE 2

$\$ S H A F T ~ I H=0, N N N=2, B R G=2 * 500 . E+03, S C A L E=.25 \$$

CASE 3

$\$ \mathrm{SHAFT} \mathrm{IH}=0, \mathrm{NNN}=3, \mathrm{BRG}=2 * 700 . \mathrm{E}+03, \mathrm{SCALE}=.25 \$$

CASE 4

$\$ S H A F T ~ I H=0, N N N=4, B R G=2 * 100 . E+04, \operatorname{SCALE}=.25 \$$

CASE 5

$\$ S H A F T ~ I H=0, N N N=5, B R G=2 * 150 . E+04, S C A L E=.25 \$$

\section{CASE 6}

$\$ S H A F T$ IH $=0, \mathrm{NNN}=6, \mathrm{BRG}=2 * 200 . \mathrm{E}+04, \mathrm{SCALE}=.25 \$$

where NNN is the number used to identify run number and is used only when a bearingstiffness-against-critical-speed plot is desired. Figures 13 and 14 are printed and computer-plotted output of case 1 . Figure 15 is the bearing-stiffness-against-criticalspeed plot for cases 1 to 6 .

Problem 6 - blade calculation with fixed end boundary condition. - This problem involves a cantilever beam having nonrotating, uncoupled bending vibration. The procedure for problem 6 is as follows:

Title card

NAMELIST card

where

$\mathrm{IC}=2$

$\mathrm{KA}=1$

Blade data cards
BLADE CALCULATION - FIXED END $\$ S H A F T ~ L=20, K B=0, I C=2, K A=1, D R P M=1000 ., R P M F=75000 . \$$ switch for fixed end boundary condition at $\mathrm{x}=0$ data read in by FORMAT 400 obtained from blade illustrated in figure 8

Figure 16 is the printed output of problem 6 . 
TEST PROELEN TAPERED SHAFT

\begin{tabular}{|c|c|c|}
\hline 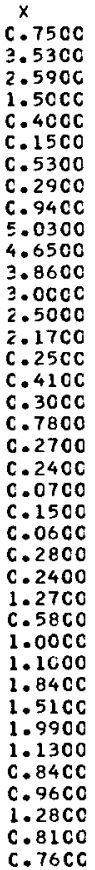 & $\begin{array}{r}00 \\
3.3800 \\
3.0000 \\
3.0000 \\
4.3600 \\
7.2500 \\
7.2500 \\
5.4000 \\
5.4000 \\
1 C .0000 \\
1 C .5000 \\
12.3800 \\
14.0000 \\
15.2000 \\
16.2000 \\
1 \epsilon .8400 \\
16.8400 \\
15.9600 \\
12.5000 \\
11.1500 \\
11.1600 \\
11.1600 \\
11.1600 \\
5.1200 \\
E .4400 \\
8.4400 \\
7.9000 \\
7.5000 \\
5.5600 \\
5.5600 \\
4.0000 \\
4.0000 \\
4.0000 \\
3.9200 \\
3.2500 \\
3.2500 \\
3.0000 \\
3.0000 \\
3.0000 \\
3.0000\end{array}$ & $\begin{array}{l}\text { ID } \\
1.3800 \\
0.7500 \\
0.7500 \\
0.7500 \\
0.7500 \\
0 . \\
0 . \\
1.8600 \\
8.6200 \\
9.8800 \\
11.8000 \\
13.5000 \\
14.7000 \\
15.7000 \\
16.2400 \\
9.2400 \\
9.2400 \\
9.2400 \\
9.2400 \\
8.1600 \\
7.2200 \\
6.1000 \\
6.1000 \\
6.1000 \\
3.6200 \\
3.6000 \\
3.6200 \\
3.6200 \\
2.2500 \\
2.2500 \\
-0 . \\
-0 . \\
-0 .\end{array}$ \\
\hline
\end{tabular}

EW
0.014800
-0.
-0.
-0.
-0.
-0.
-0.
0.015500
0.076800
0.113900
0.116800
0.103400
0.086400
0.086600
0.002500
-0.
0.015200
0.105200
-0.
-0.
-0.
-0.
-0.
-0.
-0.
-0.
-0.0
-0.
0.014400
-0.
-0.
-0.
-0.
0.055400
-0.0
0.010200
0.006700
0.079200
-0.

RHO

$0.74000 E-03$ $0.74000 E-03$ $0.74000 E-U 3$ $0.74000 E-03$ 0.74000 E 03 $0.74000 \mathrm{E}-\mathrm{3}$ $0.74000 E-3$ $0.74000 E-03$ $0.74000 E-03$ $0.74000 E-03$ 0.74000 -0 3 0.74000 E 03 $0.74000 E-03$ $0.74000 \mathrm{E}-03$ $0.74000 E-U 3$ $0.74000 \mathrm{E}-03$ 0.74000 E 03 $0.74000 \mathrm{E}-\mathrm{U} 3$ $0.74000 \mathrm{E}$ 0.74000 E-0 $0.74000 \mathrm{E}-03$ J. .74000 E- 03 $0.74000 E-03$ $0.74000 \mathrm{E}-03$ $0.74000 E-03$ $0.74000 E-03$ 0.74000 E- 03 $0.74000 \mathrm{E}-03$ $0.74000 \mathrm{E}-03$ $0.74000 \mathrm{E}-03$ $0.74000 \mathrm{E}-03$ $0.74000 \mathrm{E}-03$ O. $74000 \mathrm{E}-03$ $0.74000 E-03$ $0.74000 \mathrm{E}-03$ $0.74000 E-O$ $0.74000 \mathrm{E}-$ $0.74000 \mathrm{E}-\mathrm{O}$ $0.74000 E-03$

$\begin{array}{ll}\text { TADD } & \\ -0 . & -0 . \\ -0 . & -0 . \\ -0 . & -0 . \\ -0 . & -0 . \\ -0 . & -0 . \\ -0 . & -0 . \\ -0 . & -0 . \\ -0 . & -0 . \\ 10.5000 & 9.8800 \\ 12.3800 & 11.8000 \\ 14.0000 & 13.5000 \\ 15.2000 & 14.7000 \\ 16.2000 & 15.7000 \\ 16.8400 & 16.2400 \\ -0 . & -0 . \\ -0 . & -0 . \\ -0 . & -0 . \\ -0 . & -0 . \\ -0 . & -0 . \\ -0 . & -0 . \\ -0 . & -0 . \\ -0 . & -0 . \\ -0 . & -0 . \\ -0 . & -0 . \\ -0 . & -0 . \\ -0 . & -0 . \\ -0 . & -0 . \\ -0 . & -0 . \\ -0 . & -0 . \\ -0 . & -0 . \\ -0 . & -0 . \\ -0 . & -0 . \\ -0 . & -0 . \\ -0 . & -0 . \\ -0 . & -0 . \\ -0 . & -0 . \\ -0 . & -0 . \\ -0 . & -0 . \\ -0 . & -0 . \\ & \end{array}$

ZERO AT $X=0$ AND L

BOUNDARY CONDITIONS---SHEAR ANO MOMENT EQUAL

BRG AT STATION 2K= $0.300000 E+06$

BRG AT STATICN $31 \mathrm{~K}=0.300000 E+06$

TOTAL MASS $=0.14907389 E+01$

IST GRITICAL SPEED $=5694$.

2ND CRITICAL SPEED $=9031$

3RO CRITICAL SPEFO $=25432$.

Figure 13. - Printed output for problem 5 (bearing-stiffness-against-critical-speed plot), case 1. 


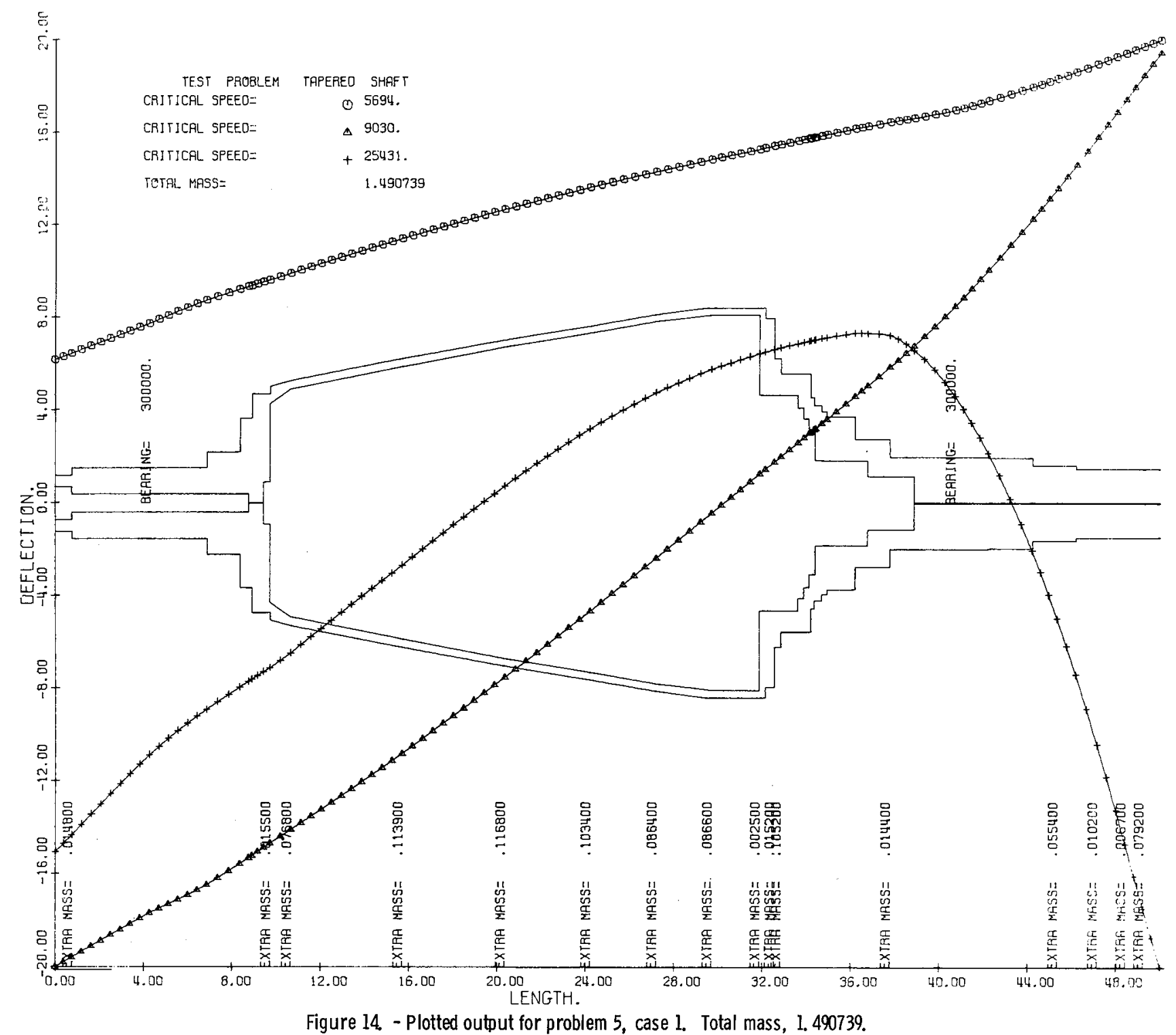




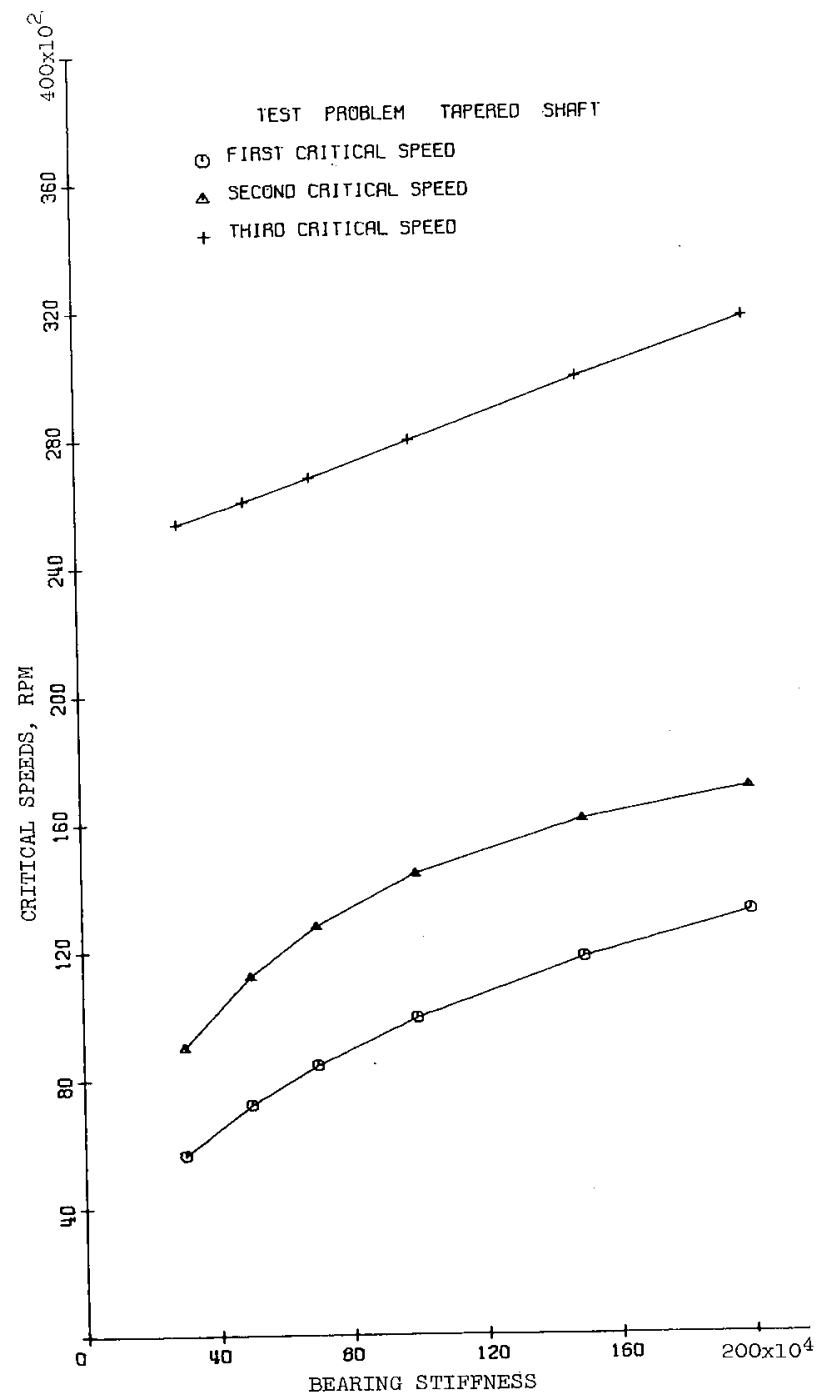

Figure 15. - Bearing stiffness as function of critical speed for all six cases.

\begin{tabular}{|c|c|c|c|c|c|}
\hline $\begin{array}{c}x \\
0.06900 \\
c .06900 \\
c .06900 \\
c .06900 \\
c .06900 \\
C .06900 \\
c .06900 \\
C .06900 \\
c .06900 \\
C .06900 \\
0.06900 \\
c .06900 \\
c .06900 \\
c .06900 \\
c .06900 \\
0.06900 \\
0.06900 \\
0.06900 \\
0.06900 \\
0.06900\end{array}$ & $\begin{array}{c}\text { AREA } \\
0.490 E-01 \\
0.477 E-01 \\
0.465 E-01 \\
0.452 E-01 \\
0.440 E-01 \\
0.488 E-01 \\
0.417 E-01 \\
0.404 E-01 \\
0.391 E-01 \\
0.378 E-01 \\
0.365 E-01 \\
0.353 E-01 \\
0.340 E-01 \\
0.327 E-01 \\
0.313 E-01 \\
0.300 E-01 \\
0.286 E-01 \\
0.272 E-01 \\
0.259 E-01 \\
0.248 E-01\end{array}$ & $\begin{array}{c}1 \\
0.178 E-04 \\
0.161 E-04 \\
0.147 E-04 \\
0.134 E-04 \\
0.123 E-04 \\
0.113 E-04 \\
0.104 E-04 \\
0.951 E-05 \\
0.864 E-05 \\
0.780 E-05 \\
0.701 E-05 \\
0.630 E-05 \\
0.564 E-05 \\
0.503 E-05 \\
0.446 E-05 \\
0.392 E-05 \\
0.342 E-05 \\
0.296 E-05 \\
0.259 E-05 \\
0.232 E-05\end{array}$ & $\begin{array}{l}E W \\
-0 . \\
-0 . \\
-0 . \\
-0 . \\
-0 . \\
-0 . \\
-0 . \\
-0 . \\
-0 . \\
-0 . \\
-0 . \\
-0 . \\
-0 . \\
-0 . \\
-0 . \\
-0 . \\
-0 . \\
-0 . \\
-0 . \\
-0 .\end{array}$ & $\begin{array}{c}E \\
0.27500 E+08 \\
0.27500 E+08 \\
0.27500 E+08 \\
0.27500 E+08 \\
0.27500 E+08 \\
0.27500 E+08 \\
0.27500 E+08 \\
0.27500 E+08 \\
0.27500 E+08 \\
0.27500 E+08 \\
0.27500 E+08 \\
0.27500 E+08 \\
0.27500 E+08 \\
0.27500 E+08 \\
0.27500 E+08 \\
0.27500 E+08 \\
0.27500 E+08 \\
0.27500 E+08 \\
0.27500 E+08 \\
0.27500 E+0 B\end{array}$ & $\begin{array}{l}\text { RHD } \\
1.75000 E-03 \\
0.75000 E-03 \\
0.75000 \mathrm{E}-03 \\
0.75000 \mathrm{E}-03 \\
0.75000 \mathrm{E}-03 \\
0.75000 \mathrm{E}-03 \\
0.75000 \mathrm{E}-03 \\
0.75000 \mathrm{E}-03 \\
0.75000 \mathrm{E}-03 \\
0.7500 \mathrm{E}-03 \\
0.7500 \mathrm{E}-03 \\
0.75000 \mathrm{E}-03 \\
0.75000 \mathrm{E}-03 \\
0.75000 \mathrm{E}-03 \\
0.75000 \mathrm{E}-03 \\
0.75000 \mathrm{E}-03 \\
0.75000 \mathrm{E}-03 \\
0.75000 \mathrm{E}-03 \\
0.75000 \mathrm{E}-03 \\
0.75000 \mathrm{E}-03\end{array}$ \\
\hline
\end{tabular}

AND SHEAR AND MOMENT EQUAL ZERO AT $X=1$

THIS RUN HAS NO BEARINGS OR COUPLINGS

IST CRITICAL SPEED $=70135$.

Figure 16. - Printed output for problem 6 (blade calculation with fixed end boundary condition). 


\section{CONCLUDING REMARKS}

A FORTRAN IV computer program using a modified method for calculating critical speeds of rotating shafts has been described. Its main features are flexibility, plotted computer output, and a minimum amount of data preparation. The program is easy to use and is a useful tool for design engineers concerned with rotating machinery.

The program can be adapted to any computer system that uses FORTRAN IV, but a plotting routine must be supplied by the user.

Lewis Research Center,

National Aeronautics and Space Administration,

Cleveland, Ohio, May 18, 1973,

501-24. 


\section{APPENDIX A}

\section{SYMBOLS}

A

B

$\mathrm{D}_{\mathrm{d}}$

$\mathrm{D}_{\mathrm{i}}$

$\mathrm{D}_{\mathrm{O}}$

$\mathrm{E}(\mathrm{x})$

$\mathrm{F}(\mathrm{x})$

$\mathrm{G}(\mathrm{x})$

h

$\mathrm{I}(\mathrm{x})$

K

L

$\mathrm{M}(\mathrm{x})$

$\mathrm{M}\left(\mathrm{x}^{+}\right)$

$\mathrm{M}\left(\mathrm{x}^{-}\right)$

$M_{n 1}, M_{n 2}, M_{n 3}$

$\mathrm{S}_{\mathrm{n}}$

$\mathrm{V}\left(\mathrm{x}^{+}\right)$

$\mathrm{V}\left(\mathrm{x}^{-}\right)$

$\mathrm{V}_{\mathrm{n} 1}, \mathrm{v}_{\mathrm{n} 2}, \mathrm{v}_{\mathrm{n} 3}$

$\mathrm{x}$

$\mathrm{Y}(\mathrm{x})$

$\mathrm{Y}_{\mathrm{S}}(\mathrm{x})$

$\mathrm{Y}_{\mathrm{n} 1}, \mathrm{Y}_{\mathrm{n} 2}, \mathrm{Y}_{\mathrm{n} 3}$

$\eta(\mathrm{x})$

$\theta(\mathrm{x})$ mass moment of inertia of disk about its axis of symmetry, $1 b-i n .-\sec ^{2}$ mass moment of inertia of disk about axis through center of gravity and normal to axis of symmetry, lb-in. $-\mathrm{sec}^{2}$

diameter of disk, in.

inside diameter of shaft section, in.

outside diameter of shaft section, in.

modulus of elasticity at $\mathrm{x}, \mathrm{lb} / \mathrm{in} .^{2}$

shear coefficient for shear deflection equation

modulus of rigidity at $x, 1 b /$ in. $^{2}$

thickness of disk, in.

diametral moment of inertia at $x$, in. 4

bearing stiffness factor (spring rate), $\mathrm{lb} / \mathrm{in}$.

length of shaft, in.

moment for a general cross section, lb-in.

moment to right of a station, $1 b-i n$.

moment to left of a station, lb-in.

moment for solutions 1,2 , and 3 at station $n$

nonshaft mass at station $\mathrm{n}, \mathrm{lb}-\mathrm{sec}^{2} / \mathrm{in}$.

shear to right of a station, $\mathrm{lb}$

shear to left of a station, $l b$

shear for solutions 1,2 , and 3 at station $n, 1 b$

station or axial position on shaft

deflection for a general cross section, in.

shear deflection for a general cross section, in.

deflection for solutions 1,2 , and 3 at station $n$, in.

mass per unit length of a general cross section, $1 b-\sec ^{2} /$ in. $^{2}$

slope at a general cross section (nondimensional) 


$\begin{array}{ll}\theta_{\mathrm{n} 1}, \theta_{\mathrm{n} 2}, \theta_{\mathrm{n} 3} & \text { slope for solutions } 1,2 \text {, and } 3 \text { at station } \mathrm{n} \text { (nondimensional) } \\ \nu & \text { Poisson's ratio } \\ \rho & \text { mass density, } 1 \mathrm{~b}-\mathrm{sec}^{2} / \mathrm{in} . \\ \omega & \text { speed of rotation or frequency of vibration, } \mathrm{rad} / \mathrm{sec}\end{array}$




\section{APPENDIX B}

\section{LISTING OF FORTRAN PROGRAM}

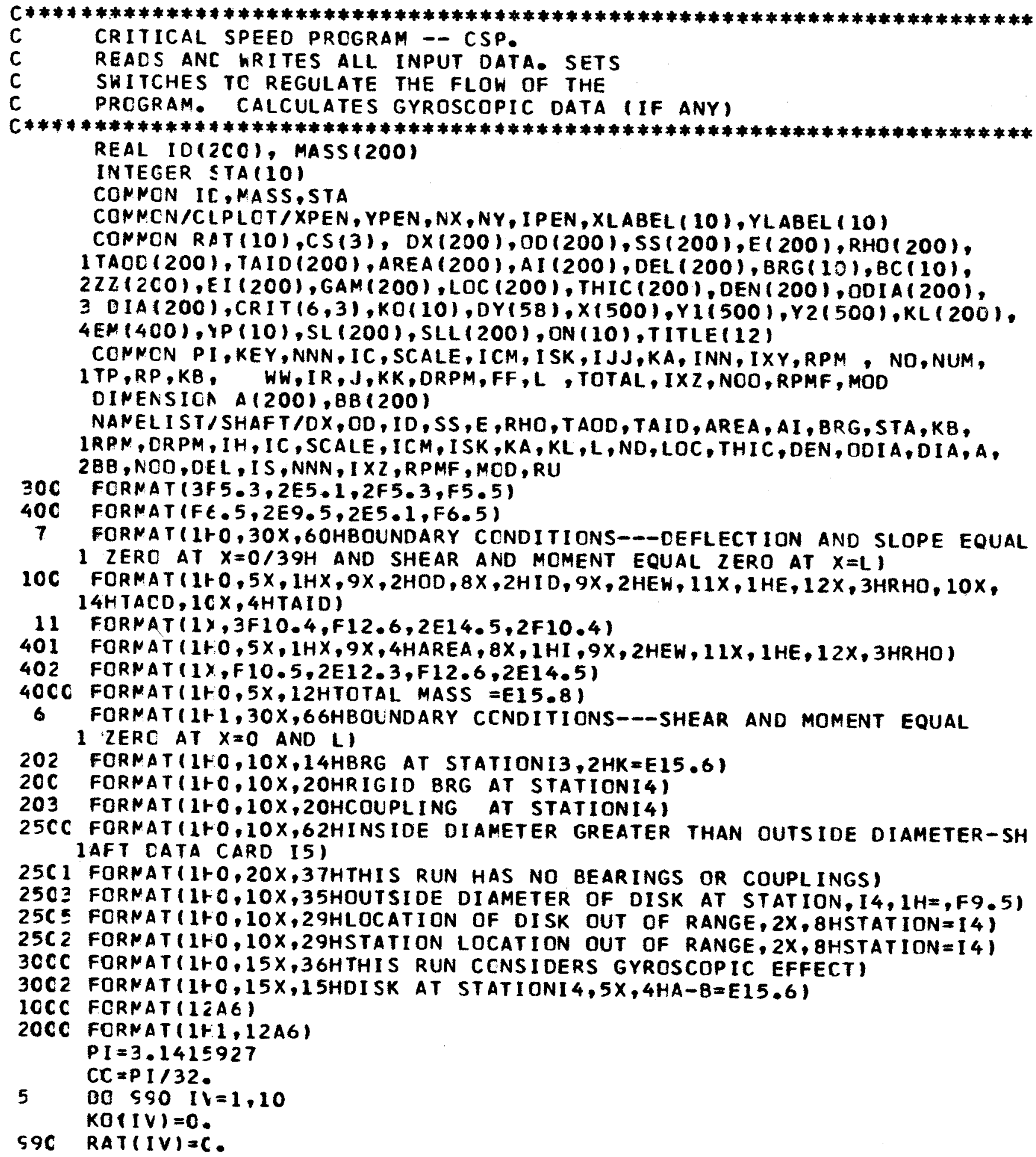




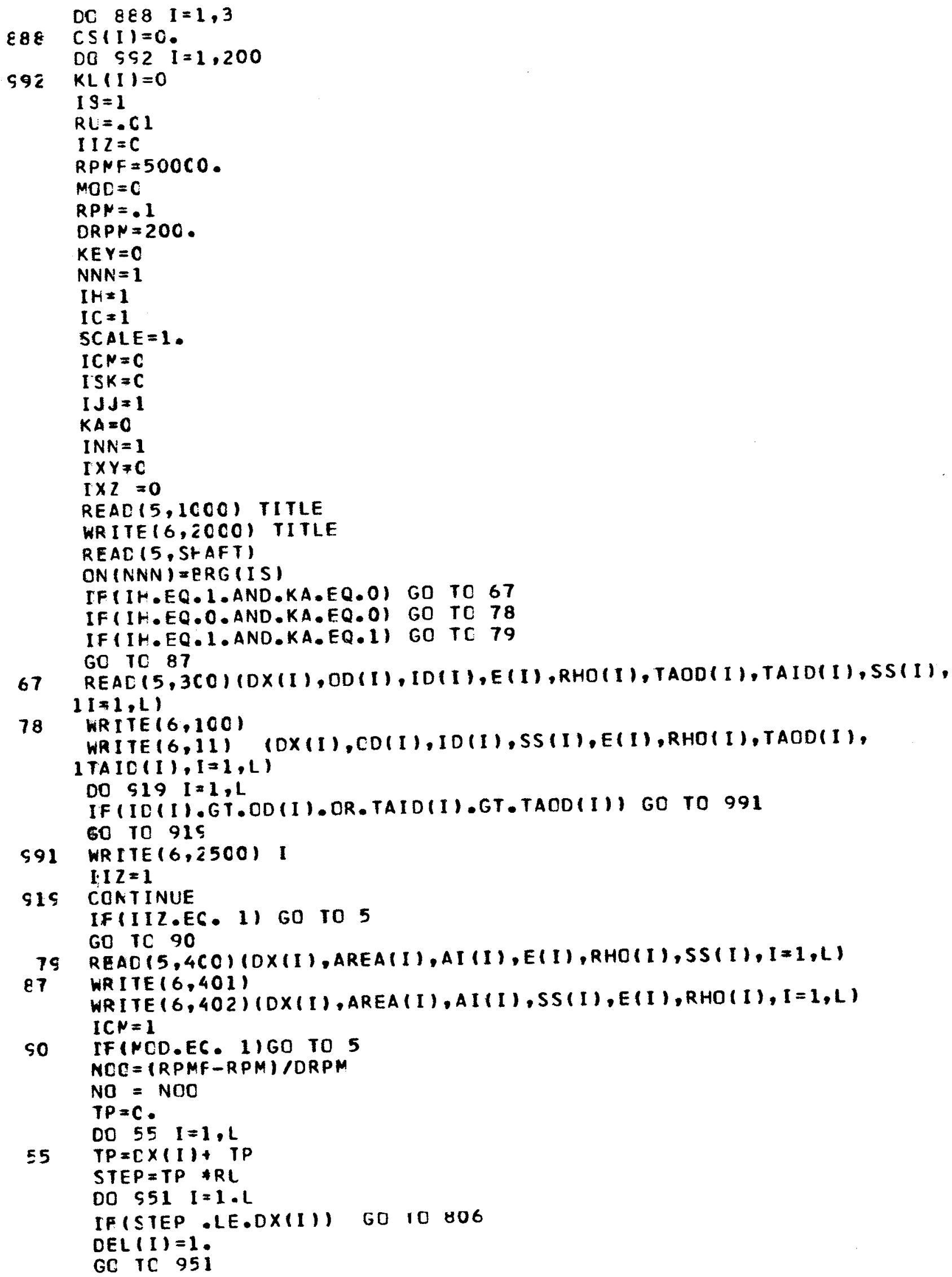




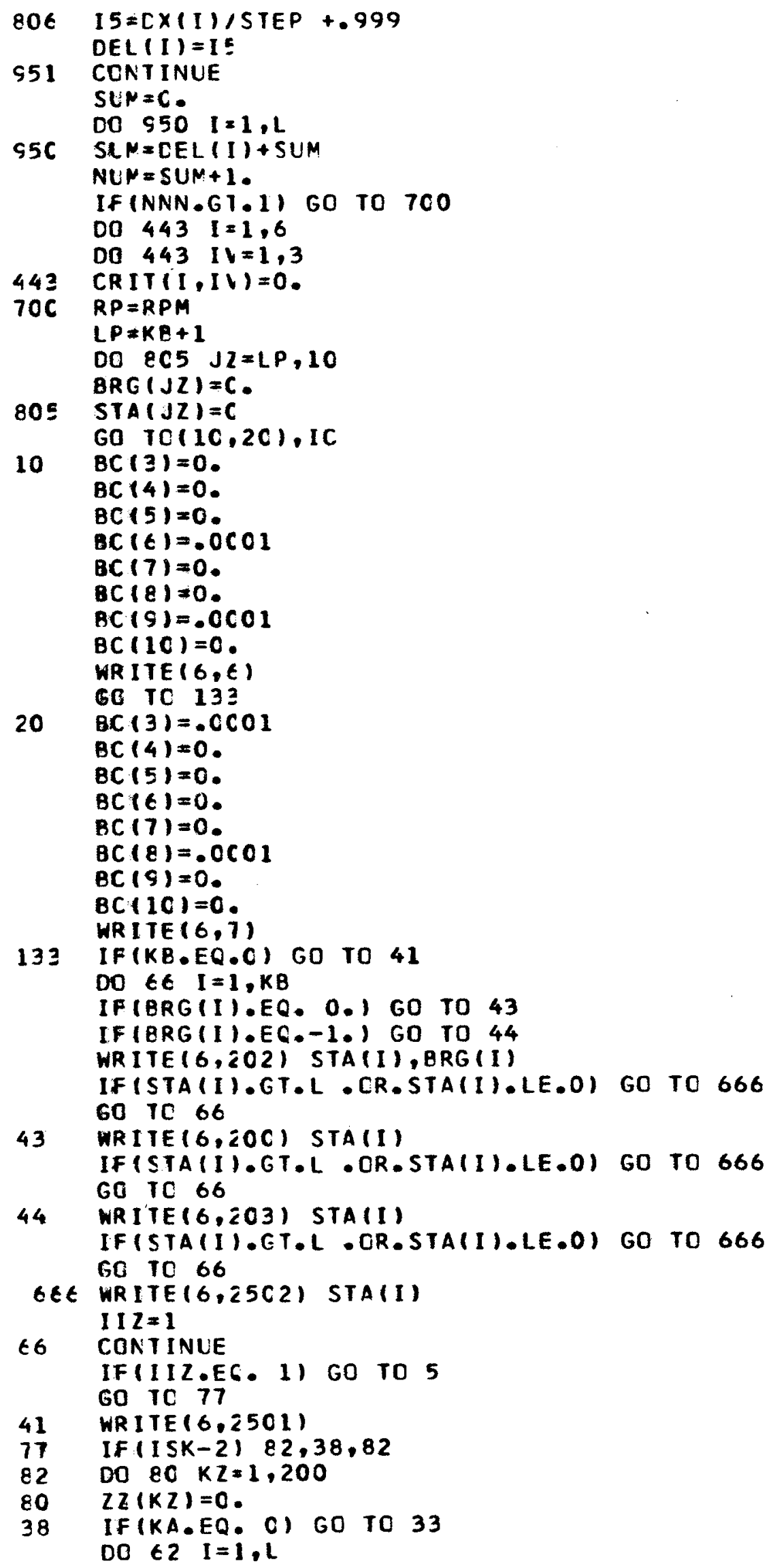




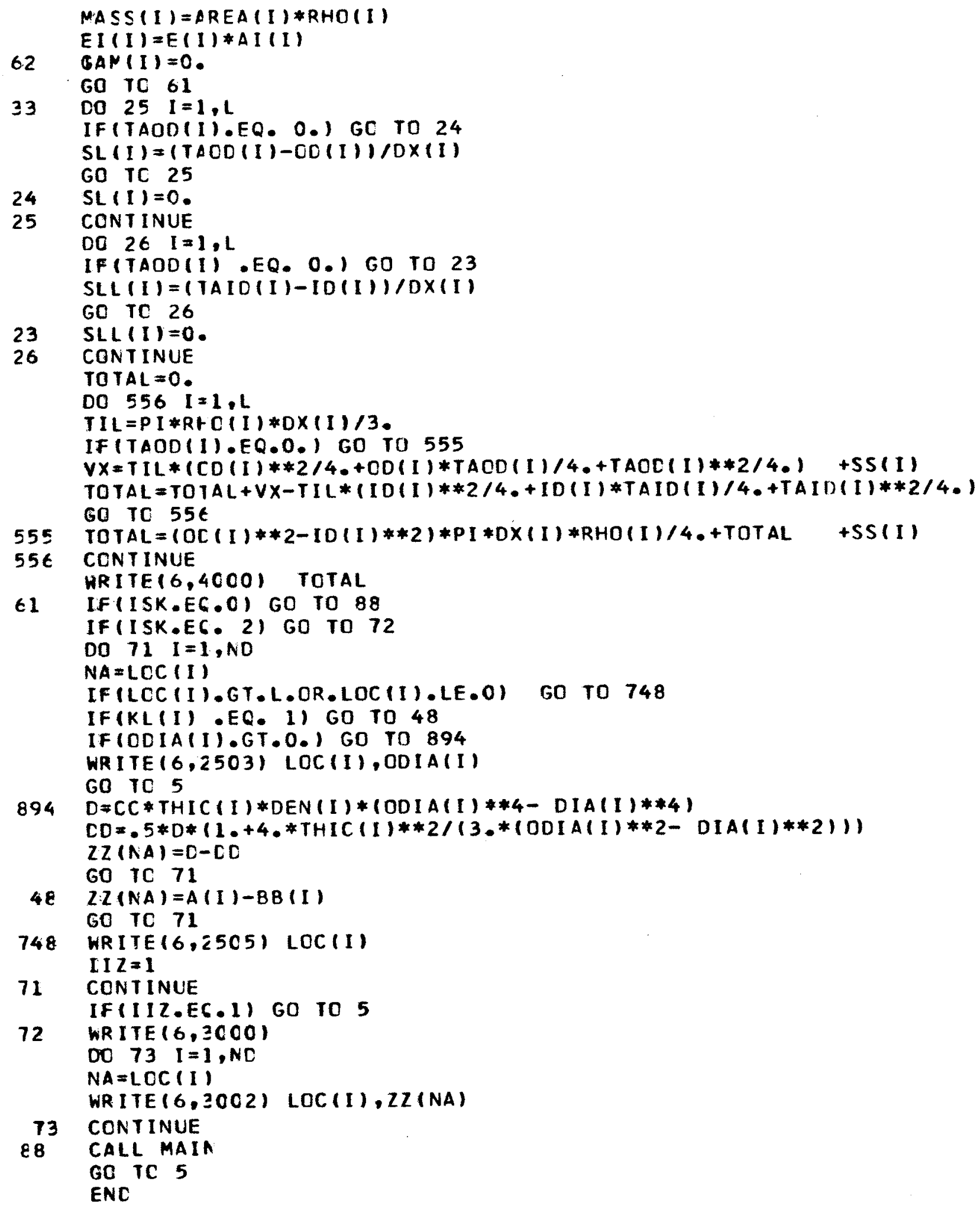




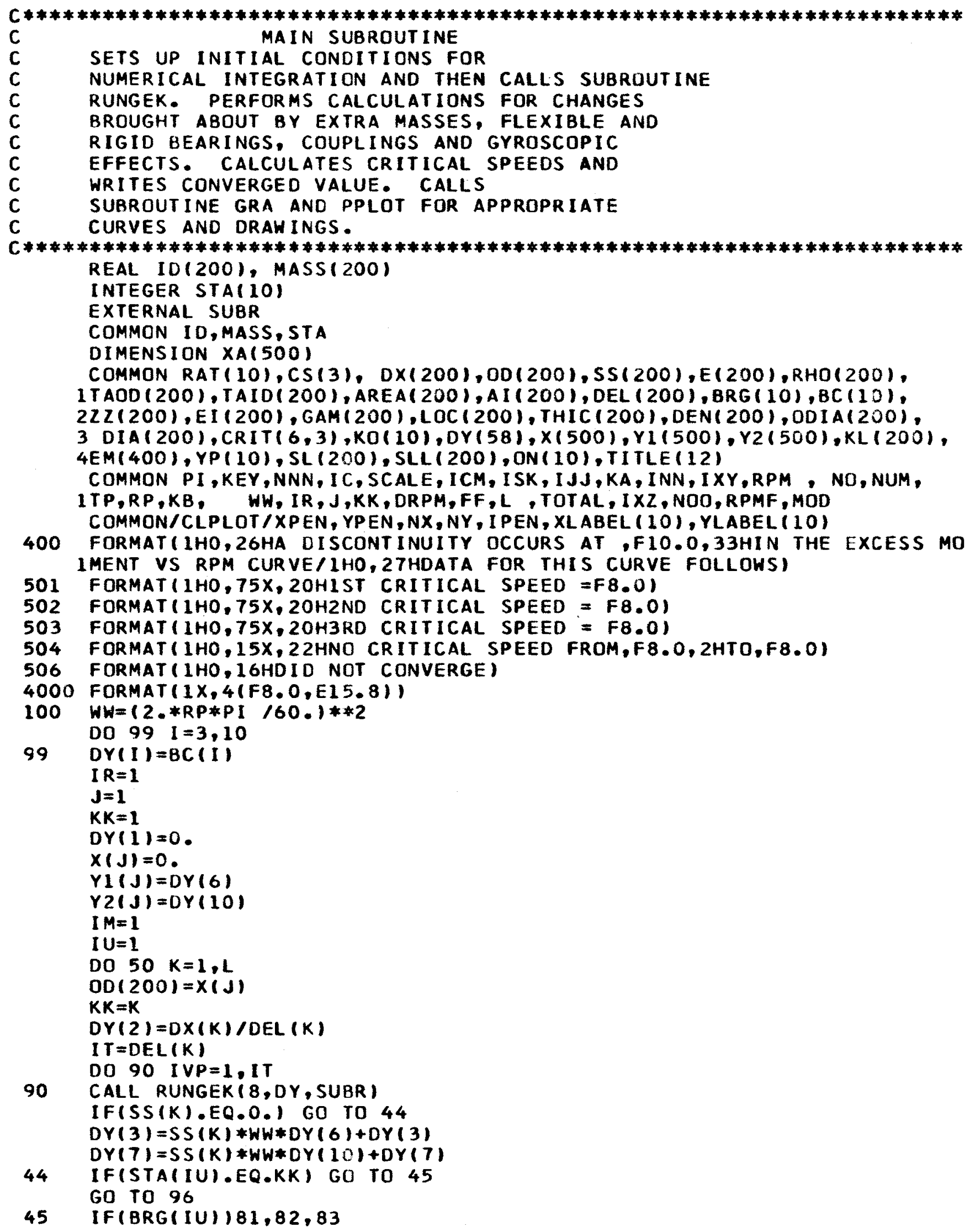


$83 \operatorname{DY}(3)=\operatorname{DY}(3)-B R G(I U) \neq \operatorname{DY}(6)$

$\operatorname{DY}(7)=D Y(7)-B R G(I U) * D Y(10)$

$$
\text { GO TO } 95
$$

$82 \operatorname{Dr}(9)=\operatorname{Dr}(9)-\operatorname{Dr}(10) * \operatorname{Dr}(5) / \operatorname{Dr}(6)$

$\operatorname{Dr}(8)=\operatorname{Dr}(8)-\operatorname{Dr}(4) * \operatorname{Dr}(10) / \operatorname{Dr}(6)$

$\operatorname{RAT}(I R)=\operatorname{DY}(10) / D Y(6)$

$K O(I R)=J$

$I R=I R+1$

$Y 2(J)=0$.

$Y 1(J)=0$.

$\operatorname{Dr}(10)=0$.

$\operatorname{Dr}(7)=0$.

$\operatorname{Dr}(3)=.0001$

$\operatorname{Dr}(4)=0$.

$\operatorname{Dr}(5)=0$.

$\operatorname{Dr}(6)=0$.

GO T0 95

$81 \quad \operatorname{DY}(7)=\operatorname{DY}(7)-\operatorname{DY}(3) * \operatorname{Dr}(8) / D Y(4)$

DY $(10)=\operatorname{DY}(10)-D Y(6) * D Y(8) / D Y(4)$

RAT $(I R)=\operatorname{DY}(8) / D Y(4)$

$K O(I R)=J$

$I R=I R+1$

$Y 2(J)=\operatorname{DY}(10)$

$Y 1(J)=0$.

DY $(8)=0$.

$\operatorname{Dr}(9)=0$.

$\operatorname{DY}(3)=0$.

$\operatorname{DY}(4)=0$.

$\operatorname{Dr}(5)=.0001$

$\operatorname{Dr}(6)=0$.

$95 \quad I U=I U+1$

96 IF(LOCIIM).EQ.KK) GO TO 97

GO TO 50

$97 \operatorname{DY}(4)=Z Z(K) * \operatorname{DY}(5) * W W+\operatorname{DY}(4)$

$\operatorname{DY}(8)=Z Z(K) * D Y(9) * W W+D Y(8)$

$I M=I M+1$

50 CONT INUE

RAT (IR) $=\operatorname{OY}(7) / D Y(3)$

$K O(I R)=J$

IF(IXY.EQ.1) GO TO 295

$E M(I N N)=\operatorname{DY}(3) * \operatorname{Dr}(8)-\operatorname{DY}(4) * \operatorname{DY}(7)$

IF(INN.LT.2) GO TO 299

298 SO=RP

IF(EM I INN)*EM(INN-1)1298,299,299

$R P=(E M(I N N) * D R P M) /(E M(I N N-1)-E M(I N N))+R P$

W $3=R P$

$J K K=0$

$I X Y=1$

$W 1=S O-O R P M$

$W 2=E M(I N N-1)$

$W 5=S O$

W6 $=E M(I N N)$

GO TO 100

$295 W 4=\operatorname{Dr}(3) * \operatorname{Dr}(8)-\operatorname{Dr}(4) * \operatorname{Dr}(7)$

IF (ABS (W4).GE.ABS (EMIINN)) .OR.ABS(W4),GE.ABS(EM(INN-1)) GO TO 300 IFIJKK.EQ. 35 ) GD TO 2968 $J K K=J K K+1$

I F(W2*W4) $2200,2200,2201$

$2200 W 5=W 3$

$W 6=W 4$ 


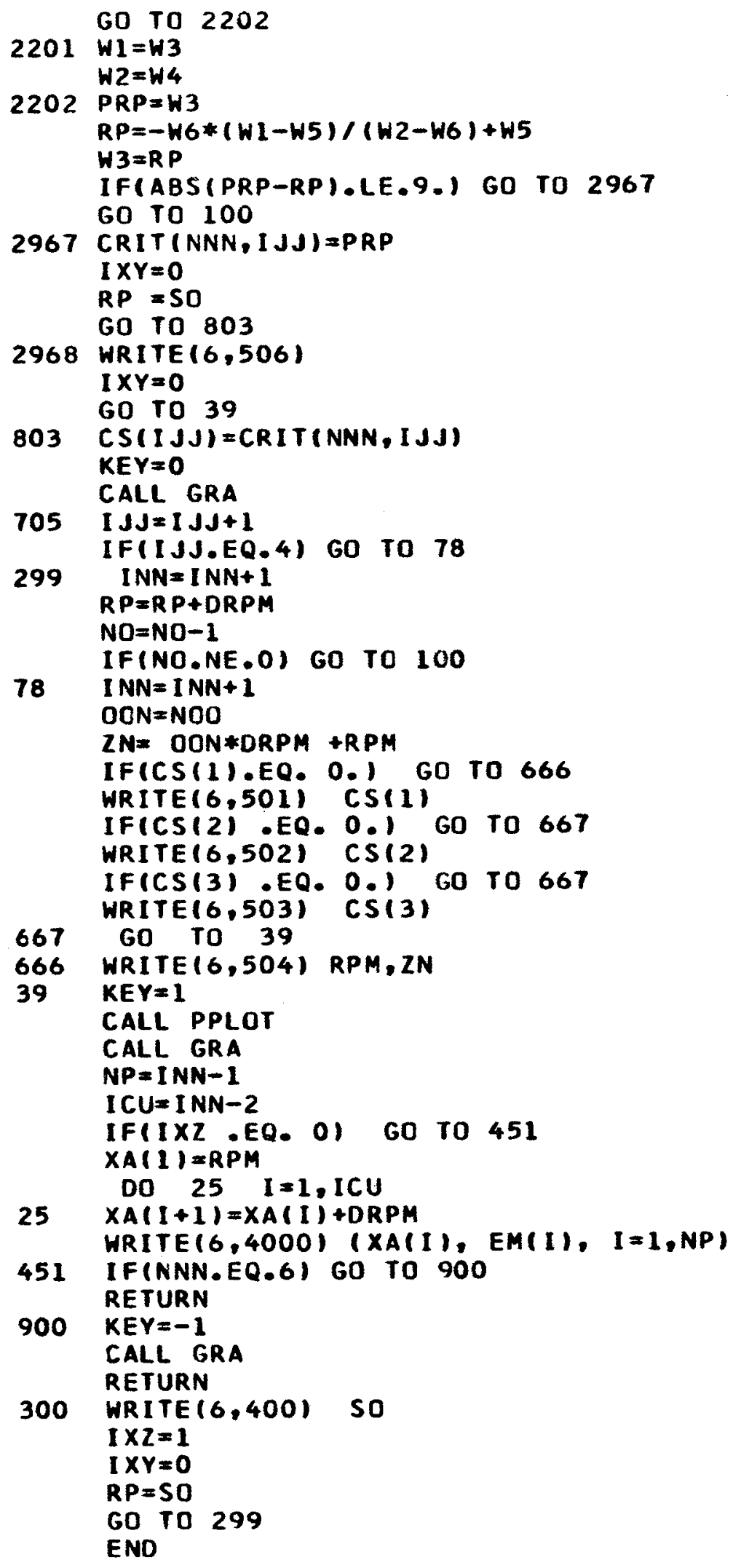




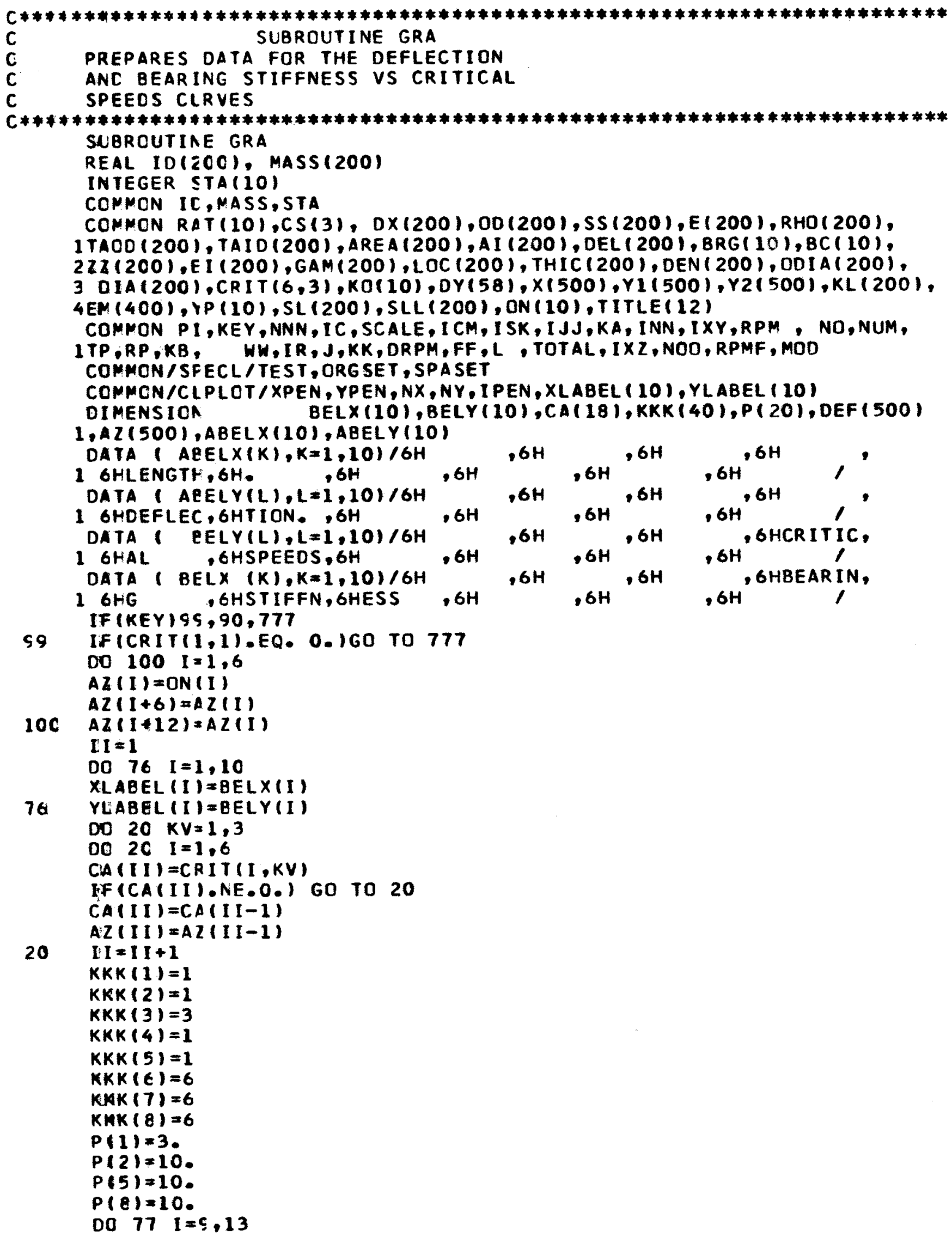


$P(I)=0$.

$P(14)=90$.

$X P E N=0$.

YPEN $=0$.

$N X=-60$

$N Y=6 C$

$F F=2$.

ORESET $=0$.

IFIICM.EG . 1$)$ GO TO 777

CALL CALFLT $(A Z, C A, K K K, P)$

GO TO 777

SO DO $\$ 1 I=1, \wedge U M$

S1 $\quad A Z(I)=X(I) * S C A L E$

$N P=1$

$L Z=1$

$N=K C(L Z)$

79 DO $8 E \quad I=A P, N$

$88 D E F(I)=Y Z(I)-Y I(I) * R A T(L Z)$

$L Z=L Z+1$

IF $(K C(L Z), E Q .0) \quad G O$ TO 74

$N P=N+1$

$N=K C(L Z)$

GC TC 79

74 TEST $T=50$.

ORG SET $=1$

DO $6 C O \quad I=1,10$

$X L A B E L(I)=A B E L X(I)$

600 YLABEL (I) $=A B E L Y(I)$

$\operatorname{KNK}(1)=4$

$\operatorname{KnK}(2)=1$

$\operatorname{KKK}(3)=1$

$\operatorname{KKK}(4)=1$

$K K K(5)=I \mathrm{JJ}$

$\operatorname{KKK}(6)=J$

$P(1)=1$.

$P(2)=T P * S C A L E$

$P(3)=0$.

$P(4)=T P * S C A L E$

$P(5)=10$.

$P(6)=-5$.

$P(7)=5$.

$P(8) \neq 10$.

DO $877 \quad I=9,13$

$877 \quad P(1)=0$.

$P(14)=90$.

$X P E N=0$.

$Y P E N=0$.

$N X=-60$

$N Y=6 C$

$H I=0$.

$F F=1$.

DO $333 I=1, J$

$233 H I=A N A X I(A B S(D E F(I)), H I)$

DO $334 I=1, J$

$334 \operatorname{DEF}(I)=5 . / H I * D E F(I)$

IF (ICM.EG • I) GO TO 777

CALL CALFLT (AZ,DEF, KKK, P)

777 RETLRN

ENC 
SLERCUTIAE PPLOT

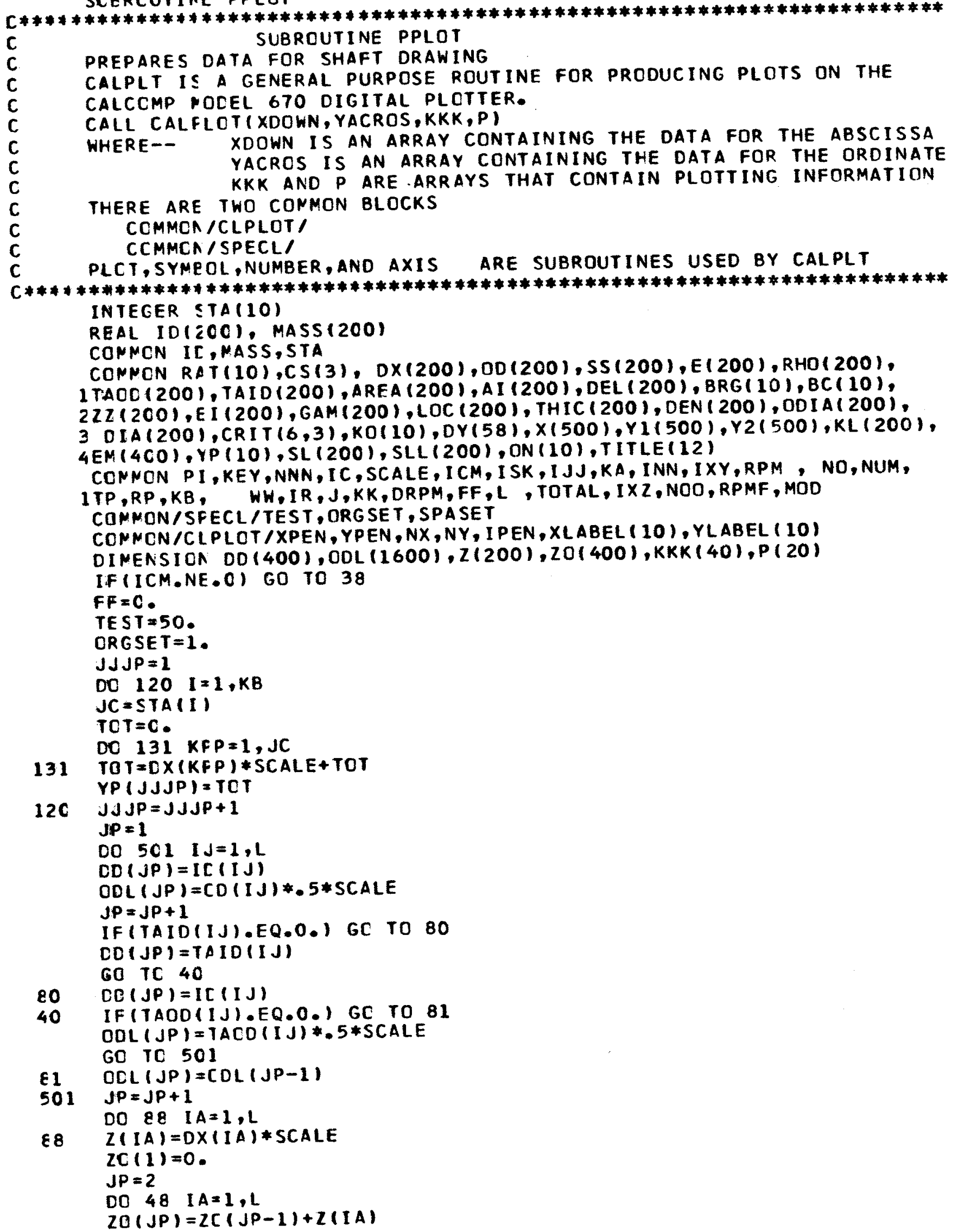


3 DIA $(200), C R I T(6,3), K O(10), O Y(58), X(500), Y 1(500), Y 2(500), K L(200)$, 4EM(400), YP(10), SL(200),SLL(200), ON(10), TITLE(12)

COMMON PI, KEY, NNN, I C, SCALE, ICM, ISK, I JJ,KA, INN, IXY,RPM, NO, NUM, $1 T P, R P, K B, \quad W W, I R, J, K K, D R P M, F F, L, T O T A L, I X Z, N O O, R P M F, M O D$

$K K=K K$

IF(KA.EQ. 1$)$ GO TO 80

$A A=O D(K K)+S L(K K) *(D Y(1)-O D(200))$

$E E=I D(K K)+S L L(K K) *(D Y(1)-O D(200))$

$G=3$. * $E(K K) / 8$.

$T Z=(E E / A A) * * 2$

$A 2=A A * A A$

$\mathrm{D} 2=E E * E E$

CROSS $=(A 2-02) * P I / 4$.

$F=(9 . *(1 .+T Z) * * 2+24 \cdot * T Z) /(8 . *(1 \bullet+T Z) * * 2)$

$G A M(K K)=F /(G * C R O S S)$

$A 4=A 2 * A 2$

$D 4=02 * 02$

MASS $(K K)=(A 2-D 2) * P I * R H O(K K) / 4$.

$E I(K K)=(A 4-D 4) * P I / 64 * * E(K K)$

80

$\operatorname{DY}(11)=\operatorname{MASS}(K K) * \operatorname{DY}(6) * W W$

$\operatorname{Dr}(12)=\operatorname{Dr}(3)$

$\operatorname{DY}(13)=\operatorname{DY}(4) / E I(K K)$

$\operatorname{DY}(14)=\operatorname{DY}(5)-\operatorname{DY}(3) * \operatorname{GAM}(K K)$

DY $(15)=$ MASS $(K K) * D Y(10) * W W$

DY $(16)=$ DY $(7)$

DY $(17)=\operatorname{DY}(8) / E I(K K)$

$\operatorname{DY}(18)=\operatorname{DY}(9)-\operatorname{DY}(7) * \operatorname{GAM}(K K)$

RETURN

END

SUBRCUTINE RUNGEK(NN, $Y$, SUBR)

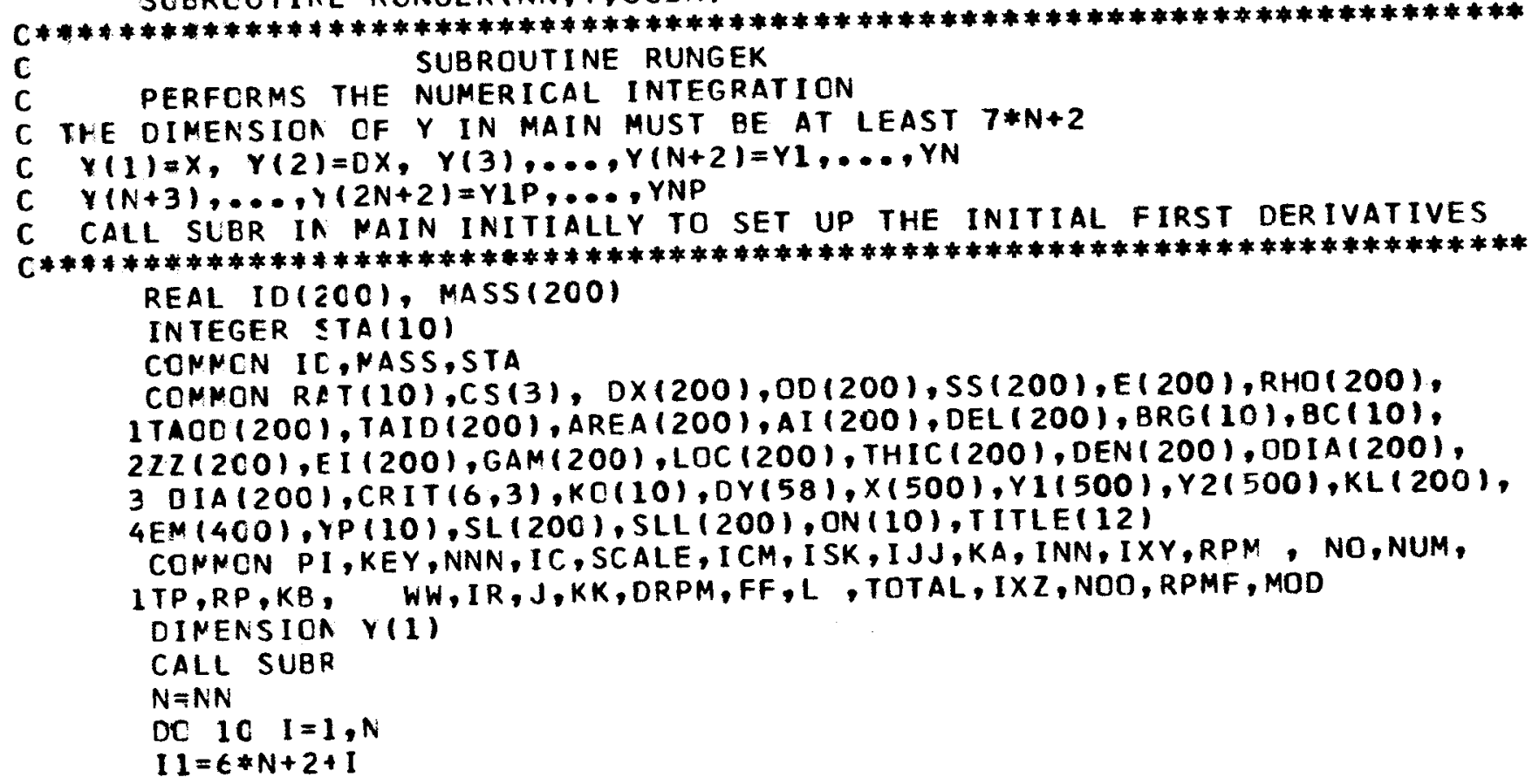


1C $Y(I 1)=Y(I+2)$

DO $12 \quad I=1, N$

$\mathrm{I} I=\mathrm{N}+2+\mathrm{I}$

$12=2 * N+2+I$

$12 Y(12)=Y(2) * Y(I 1)$

$Y(1)=Y(1)+Y(2) / 2$.

DO $14 I=1, N$

$I 1=2 * N+2+1$

$r .2=6 * N+2+1$

$14 Y(I+2)=Y(I 2)+.5 * Y(I 1)$

CALL SUBR

OO $16 \quad I=1, N$

$11=\mathrm{N}+2+1$

$12=3 * N+2+I$

le $Y(12)=Y(2) * Y(11)$

DO $181=1, N$

$I 1=3 * N+2+I$

$12=6 * N+2+I$

$18 Y(1+2)=Y(12)+.5 * Y(11)$

CALL SUBR

DO 2C $I=1, N$

$I 1=N+2+I$

$I 2=4 * N+2+I$

2C $Y(12)=Y(2) * Y(I 1)$

$Y(1)=Y(1)+Y(2) / 2$.

DO $22 I=1, N$

$I 1=4 * N+2+1$

$12=6 * N+2+I$

$22 Y(I+2)=Y(12)+Y(11)$

CALL SUBR

DC $24 \quad I=1, n$

$\mathrm{I} 1 \neq \mathrm{N} \neq \mathbf{2}+\mathrm{I}$

$12=5 * N+2+1$

$24 Y(12)=Y(2) * Y(I 1)$

DO $26 \quad I=1, N$

$11=2 * N+2+1$

$12=3 * N+2+I$

$13=4 * N+2+1$

$14=5 * N+2+1$

$I 5=6 * N+2+I$

$26 Y(I+2)=Y(I 5)+(Y(I 1)+2 \cdot * Y(I 2)+2 * * Y(I 3)+Y(I 4)) / 6$.

$J \neq J+1$

$Y 1(J)=Y(\epsilon)$

$Y 2(J)=Y(10)$

$X(J)=Y(1)$

RE TLRN

ENC 


\section{SLERCUTIAE CALTIT}

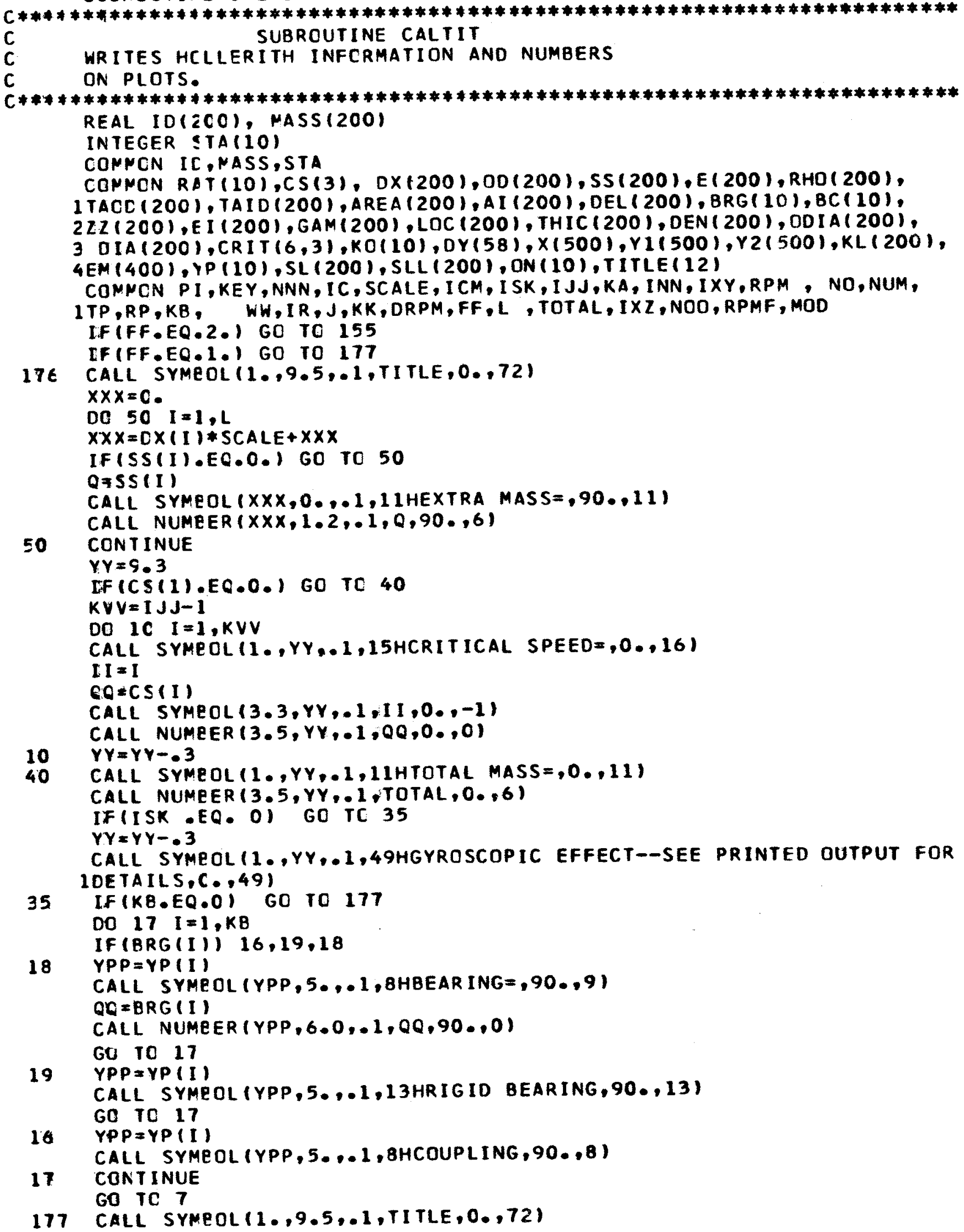


7 RETLRN

15 CALL SYMECL $(1,0,9.5,01$, TITLE,0.,72)

CALL SYMPOL $11,9,2,01,1,0,1,-1)$

CALL SYMEOL $11.2,9.2, .1,20$ HFIRST CRITICAL SPEED,0.121)

CALL. SYMEOL $(1,0,8,9,01,2,0,,-1)$

CALL SYMEOL $(1,2,8,9,01,21$ HSECOND CRITICAL SPEED,0.,22)

CALL SYMEOL $(1,8,6,61,3,0, \ldots-1)$

CALL SYMEOL $(1,2,8,6,01,20 H T H I R D$ CRITICAL SPEED,0,121)

GO TO 7

END 


\section{REFERENCES}

1. Prohl, H. A. : A General Method for Calculating Critical Speeds of Flexible Rotors. J. Appl. Mech., vol. 12, no. 3, Sept. 1945, pp. 142-148.

2. Roark, Raymond J.: Formulas for Stress and Strain. Third ed., McGraw-Hill Book Co., Inc., 1954, pp. 119-120.

3. Cowper, G. R.: The Shear Coefficient in Timoshenko's Beam Theory. J. Appl. Mech., vol. 33, no. 2, June 1966, pp. 335-340. 